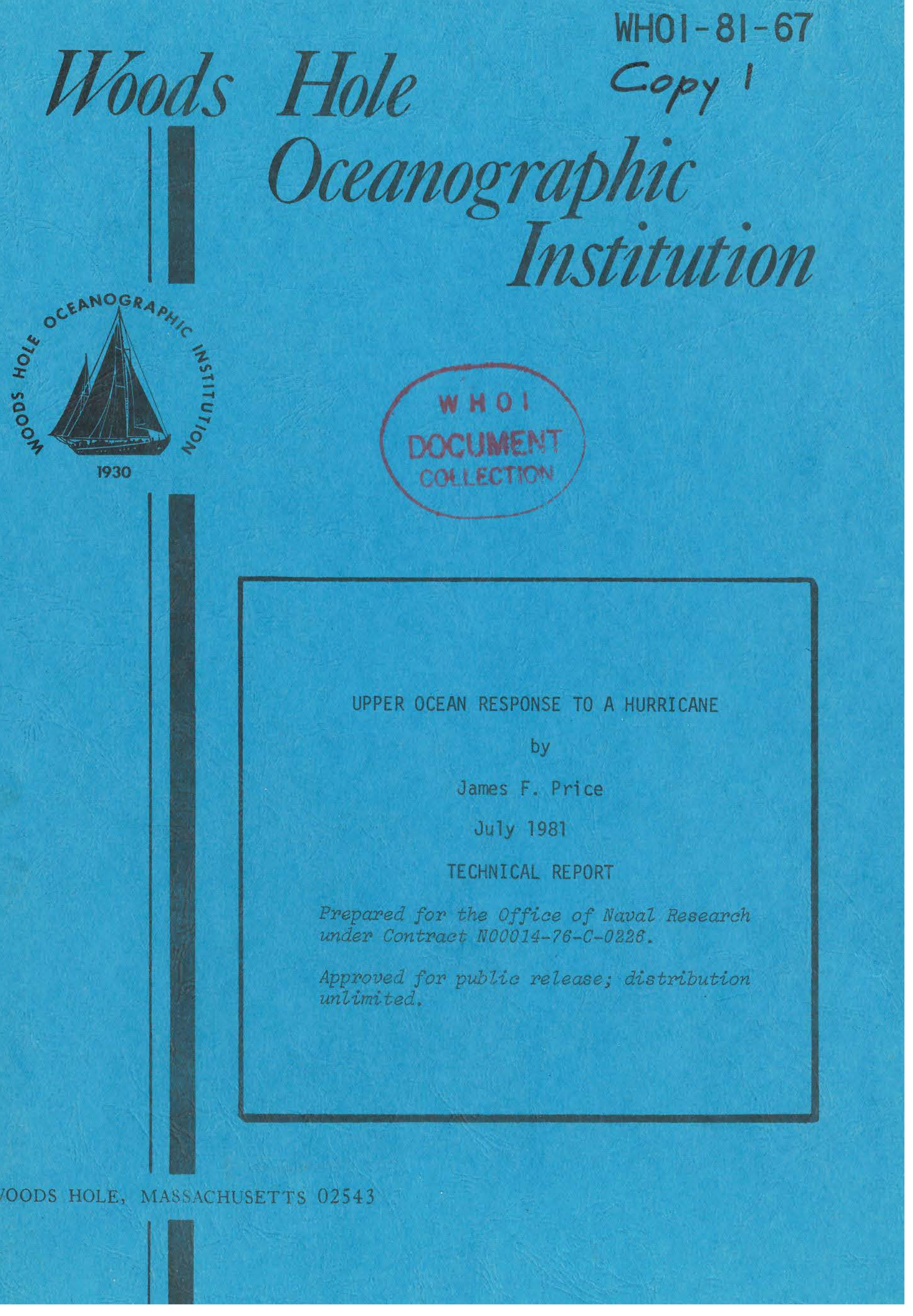


WHOI $-87-67$

UPPER OCEAN RESPONSE TO A HURRICANE

by

James F. Price

WOODS HOLE OCEANOGRAPHIC INSTITUTION

Woods Hole, Massachusetts 02543

July 1981

TECHNICAL REPORT

Prepared for the office of Naval Research under Contract No0074-76-C-0226.

Reproduction in whole or in part is permitted for any purpose of the United States Govermment. In citing this report in a bibliography, the reference given should be to: Journal of Physical Oceanography II(2): 153-175 (F'ebruary 1981).

Approved for Distribution: Valentine Worthington, Chairman Department of Physical Oceanography 
Reprinted from Journal of Physical Oceanography, Vol. 11, No. 2, February 1981

American Meteorological Society

Printed in U. S. A.

\title{
Upper Ocean Response to a Hurricane
}

\author{
JAMes F. Price \\ Woods Hole Oceanographic Institution, Woods Hole, MA 02543
}

(Manuscript received 4 August 1980, in final form 10 November 1980)

\begin{abstract}
The upper ocean response to a moving hurricane is studied using historical air-sea data and a three-dimensional numerical ocean model. Sea surface temperature (SST) response is emphasized. The model has a surface mixed-layer (ML) that entrains according to a velocity dependent parameterization, and two lower layers that simulate the response in the thermocline.

The passage of Hurricane Eloise (1975) over buoy EB-10 is simulated in detail. SST decreased $2^{\circ} \mathrm{C}$ as Eloise passed directly over EB-10 at $8.5 \mathrm{~m} \mathrm{~s}^{-1}$. Model results indicate that entrainment caused $85 \%$ of the irreversible heat flux into the ML; air-sea heat exchange accounted for the remainder. The maximum SST response was predicted to be $-3^{\circ} \mathrm{C}$ and to occur $60 \mathrm{~km}$ to the right of the hurricane track. This is consistent with the well-documented rightward bias in the SST response to rapidly moving hurricanes. The rightward bias occurs in the model solution because the hurricane wind-stress vector turns clockwise with time on the right side of the track and is roughly resonant with the ML velocity. High ML velocities cause strong entrainment and thus a strong SST response.

Model comparisons with EB-10 data suggest that a wind-speed-dependent drag coefficient similar to Garratt's (1977) is appropriate for hurricane conditions. A constant drag coefficient $1.5 \times 10^{-3}$ underpredicts the amplitude of upwelling and the SST response by $\sim 40 \%$.

Numerical experiments show that the response has a lively dependence on a number of air-sea parameters. Intense, slowly moving hurricanes cause the largest response. The SST response is largest where cold water is near the sea surface, i.e., where the initial ML is thin and the upper thermocline temperature gradient is sharp.

Nonlocal processes are important to some aspects of the upper ocean response. Upwelling significantly enhances entrainment under slowly moving hurricanes $\left(\leqslant 4 \mathrm{~m} \mathrm{~s}^{-1}\right)$ and reduces the rightward bias of the SST response. Horizontal advection dominates the pointwise ML heat balance during the several-day period following a hurricane passage. Pressure gradients set up by the upwelling do not play an important role in the entrainment process, but are an effective mechanism for dispersing energy from the ML over a 5-10 day time scale.
\end{abstract}

\section{Introduction}

Here we examine the response of the open ocean to a steadily moving hurricane. The response within the upper ocean and the response of sea surface temperature (SST) are emphasized. The primary goal is to interpret some important, recent additions to the historical data base, and particularly to describe the effects of nonlocal processes - upwelling, horizontal advection and pressure gradients.

The response of SST is of special interest because of the role of SST in hurricane-ocean energy exchange (Ooyama, 1969). Numerical experiments and field studies suggest that transfer from a warm sea surface is required to boost the static energy of the planetary boundary layer to a level which permits a storm to reach and maintain hurricane intensity (Malkus, 1962). Hurricanes are known to lower SST significantly in comparison with tropical air-sea temperature differences; thus there may occur negative feedback between the SST response and hurricane intensity (Chang and Anthes, 1979). The oceanic half of this important air-sea interaction problem is to predict the SST response to a given hurricane.

Historical observations are reviewed in Section 2. When considered as a whole, these observations provide a remarkably complete description of the SST response, and raise the following specific questions:

1) What physical mechanism(s) dominates the SST response to a hurricane? What causes the pronounced rightward bias in the SST response?

2) How does the response depend upon such factors as the hurricane translation speed, the ocean initial condition, etc.?

3) What role do nonlocal dynamics (upwelling, horizontal advection and pressure gradients) play in the upper ocean response?

4) Is there evidence that air-sea transfer coefficients increase significantly under hurricane conditions?

The main contribution of the present work is a numerical model (Section 3) which is intended to 
TABLE 1. Hydrographic studies of the sea surface temperature response to hurricanes.

\begin{tabular}{|c|c|c|c|c|c|}
\hline Study: Hurricane & Method: Region & $\begin{array}{c}\text { Average } \\
U_{H} \\
\left(\mathrm{~m} \mathrm{~s}^{-1}\right)\end{array}$ & $\begin{array}{c}\text { Hurricane } \\
\text { central } \\
\text { pressure } \\
(\mathrm{mb})\end{array}$ & $\begin{array}{l}\Delta \mathrm{SST}_{\max } \\
\left({ }^{\circ} \mathrm{C}\right)\end{array}$ & Position of* $\Delta \mathrm{SST}_{\max }$ \\
\hline Leipper (1967): Hilda (1964) & $\begin{array}{l}\text { extensive post-hurricane } \\
\text { hydrographic survey: Gulf of } \\
\text { Mexico }\end{array}$ & 3 & 930 & -6 & $\begin{array}{l}\text { pattern is generally } \\
\text { unclear, may be } 50 \mathrm{~km} \\
\text { to left of track (Fig. 8) }\end{array}$ \\
\hline $\begin{array}{l}\text { Fedorov et al. (1979): } \\
\text { Ella (1968) }\end{array}$ & $\begin{array}{l}\text { Extensive pre- and post-hurricane } \\
\text { XBT survey: mid-Atlantic }\end{array}$ & 6 & 980 & -2 & $\begin{array}{l}30 \mathrm{~km} \text { to right (Fig. } 3 \text {, } \\
\text { same as this Fig. 1a) }\end{array}$ \\
\hline $\begin{array}{l}\text { Pudov et al. (1979): Tess } \\
\text { (1975) }\end{array}$ & $\begin{array}{l}\text { extensive post-hurricane STD survey: } \\
\text { mid-Pacific }\end{array}$ & 6 & 940 & -4 & $\begin{array}{l}75 \mathrm{~km} \text { to right (Fig. 1, } \\
\text { same as this Fig. 2a) }\end{array}$ \\
\hline Wright (1969): Shirley (1965) & $\begin{array}{l}1 \text { pre-, } 1 \text { post-hurricane XBT section: } \\
\text { vicinity of the Kuroshio }\end{array}$ & 13 & 935 & -3 & $20 \mathrm{~km}$ to right (Fig. 4) \\
\hline $\begin{array}{l}\text { Jordan }(1964): \\
\text { Wanda (1956) } \\
\text { Clara (1955) }\end{array}$ & $\begin{array}{l}\text { extensive pre- and post-hurricane } \\
\text { SST reports from ships of } \\
\text { opportunity: mid-Pacific }\end{array}$ & $\begin{array}{l}16 \\
18\end{array}$ & $\begin{array}{l}920 \\
915\end{array}$ & $\begin{array}{l}-2 \\
-1\end{array}$ & $\begin{array}{l}150 \mathrm{~km} \text { to right } \\
50 \mathrm{~km} \text { to right } \\
\text { (Figs. } 2 \text { and } 3 \text { ) }\end{array}$ \\
\hline
\end{tabular}

* Estimates made by this author from their figures noted.

simulate realistically the upper ocean response. A well-documented and largely typical case, the passage of Hurricane Eloise (1975) over National Oceanic and Atmospheric Administration Data Buoy Office (NDBO) buoy EB-10, is simulated in detail. The oceanic initial condition and the model hurricane are described in Section 4. An overview of the response is given in Section 5, and a comparison of the model solution with EB-10 oceanic data is given in Section 6. Numerical experiments which demonstrate sensitivity to air/sea parameters and to nonlocal processes are discussed in Section 7. A summary of results and some remarks are given in Section 8.

\section{Review of observations}

Observations described here have come from hydrographic surveys and from air-sea data buoys operated by NDBO. These provide complementary views of the ocean's response. Surveys show the horizontal and vertical structure of the response (temperature only in most cases) but, of course, give no clue to time dependence and provide little or no information -on the hurricane itself. The airsea buoys show the ocean's response at a fixed point as a function of time (again, mainly temperature) along with simultaneous, high-quality meteorological observations of the hurricanes.

\section{a. Hydrographic surveys}

Hydrographic surveys have been reported by Jordan (1964), Leipper (1967), Wright (1969), Pudov et al. (1979) and Fedorov et al. (1979) (see Table 1). Two prominent features of the SST response are that:

1) The range of the maximum $\mathrm{SST}$ response $\Delta \mathrm{SST}_{\max }$ is broad, -1 to $-6^{\circ} \mathrm{C}$. The data of
Table 1 suggest that the response increases with decreasing hurricane translation speed $U_{H}$ and with increasing hurricane intensity (given by minimum central pressure).

2) The SST response is markedly asymmetrical about the hurricane track. For rapidly moving hurricanes (hurricane translation speed $U_{H} \geq 6 \mathrm{~m} \mathrm{~s}^{-1}$ ), $\Delta \mathrm{SST}_{\max }$ is found $30-150 \mathrm{~km}$ to the right of the track (looking in the direction of the hurricane's motion). Leipper's (1967) observations of the SST response to slowly moving hurricane Hilda $\left(U_{H} \approx 3 \mathrm{~m} \mathrm{~s}^{-1}\right)$ do not show a rightward bias in the point of maximum response; they do show that cooling was most extensive on the right side of the track.

Recent, detailed observations of the rightward bias in $\Delta \mathrm{SST}_{\max }$ are described by Federov et al. (1979), who surveyed the POLYMODE region before and after the passage of Ella (Fig. 1), and by Pudov et al. (1979), who surveyed the track of Hurricane Tess during project Typhoon ' 75 (Fig. 2). The Ella observations are particularly valuable because the initial oceanic temperature field was well observed, and was approximately uniform horizontally. Ella was a relatively small, weak hurricane which caused SST cooling over a region of only about 200 $\mathrm{km}$ width. $\Delta \mathrm{SST}_{\max }$ was $-1.7^{\circ} \mathrm{C}$ and occurred $30 \mathrm{~km}$ to the right of the track. At the same distance to the left of the track the response was $-0.4^{\circ} \mathrm{C}$, a factor of 4 less. Tess was a much larger and more intense hurricane which caused pronounced SST cooling over a region $400 \mathrm{~km}$ wide. $\Delta \mathrm{SST}_{\max }$ was estimated to be $-4^{\circ} \mathrm{C}$ and occurred roughly $75 \mathrm{~km}$ to the right of the track. At the same distance to the left, $\Delta$ $\mathrm{SST} \approx-1.5^{\circ} \mathrm{C}$ roughly, or about a factor of 3 less.

The Ella sections show that ML deepening by entrainment was much stronger on the right side of 

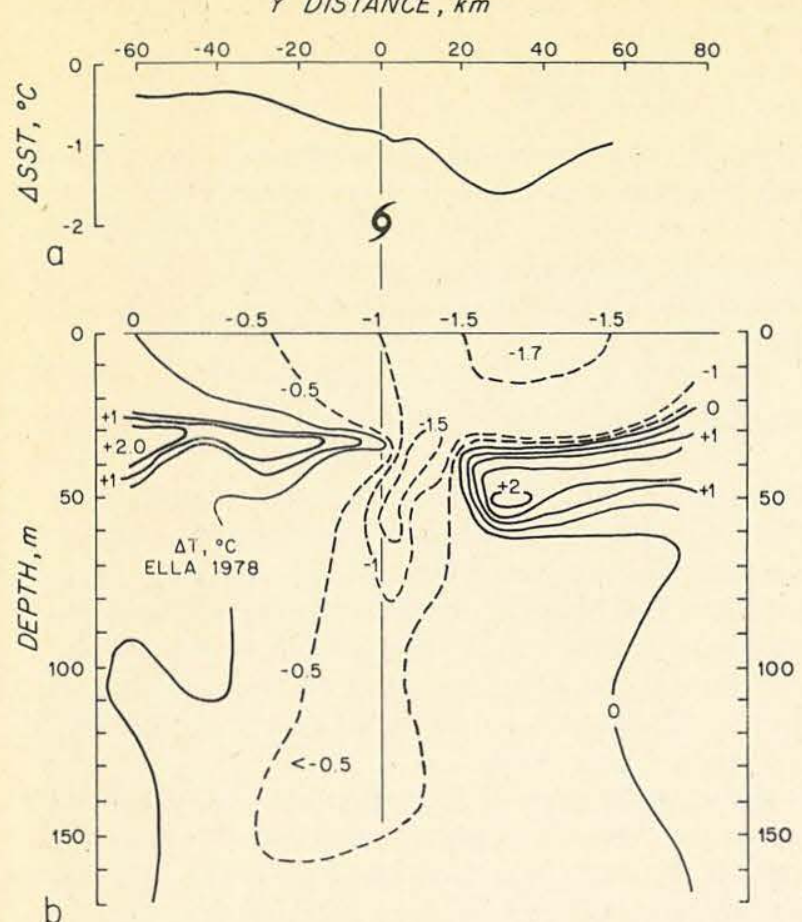

FIG. 1a. Response of SST across the track of hurricane Ella (after Fedorov et al., 1979, Fig. 3). SST was observed approximately one day before and after the hurricane passage.

FIG. 1b. Response of subsurface temperature across the track of hurricane Ella (after Fedorov et al., 1979, Fig. 4). Contour interval is $0.5^{\circ} \mathrm{C}$, negative values are dashed. XBT casts were made at roughly $20 \mathrm{~km}$ intervals along a section occupied approximately one day before and after the hurricane passage.
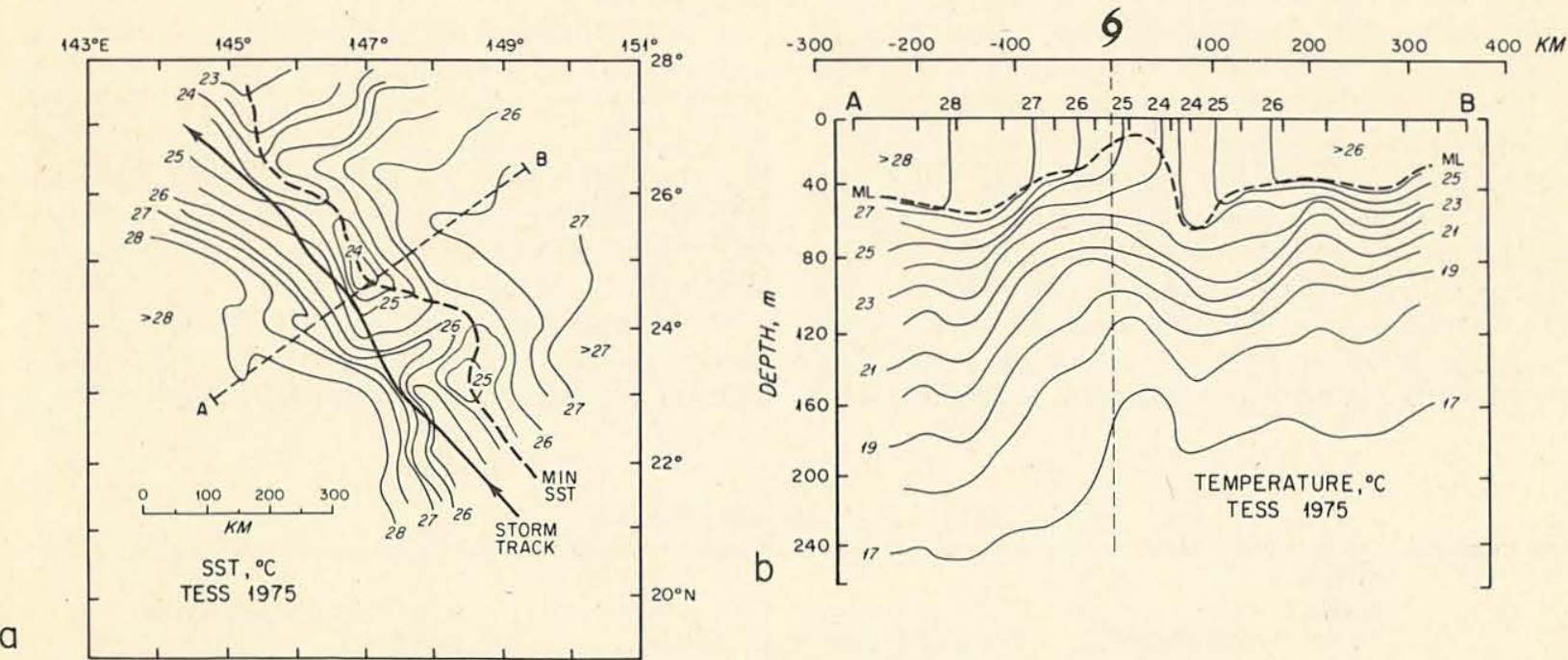

FIG. 2a. SST around the track of hurricane Tess, after Pudov et al. (1979, Fig. 1). Tess moved toward the northwest at $\sim 6 \mathrm{~m} \mathrm{~s}{ }^{-1}$. STD casts were made at $20 \mathrm{~km}$ intervals along five sections as part of project Typhoon ' 75 . The survey was conducted 3-5 days after the storm passage. Note that the minimum in SST occurred $50-150 \mathrm{~km}$ to the right of the hurricane track.

FIG. 2b. Temperature section AB made across the track of Tess (after Pudov et al., 1979, Fig. 3). The base of the ML is shown as a heavy dashed contour. The large-scale upward trend of isotherms to the north is climatological. The $200 \mathrm{~km}$ wide, $40 \mathrm{~m}$ amplitude upwelling beneath the track is a response to the positive stress-curl of the hurricane. Note that the upwelling is in phase and of roughly equal amplitude from the base of the mixed layer to the deepest depth shown here, $240 \mathrm{~m}$. 


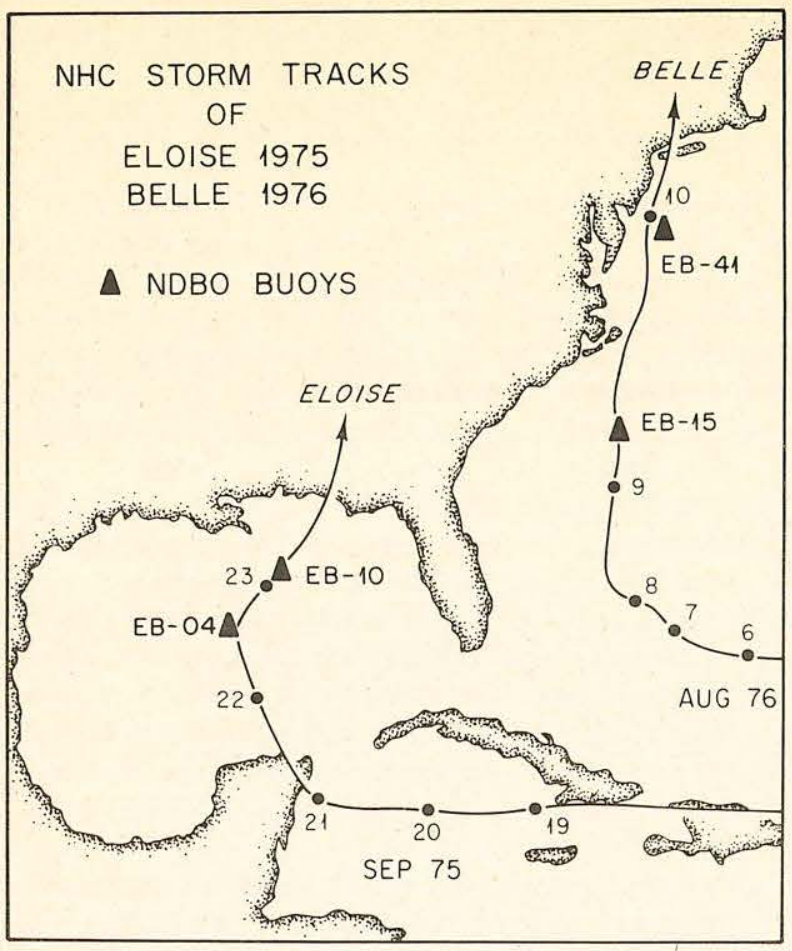

FIG. 3. National Hurricane Center storm tracks of hurricanes Eloise (1975) and Belle (1976). The dates are marked at 0000 GMT. Buoy positions are shown as triangles.

the eye, and wind direction was nearly antisymmetric (Fig. 4). Eloise was beginning to sweep up relatively dry, cool continental air as she neared the coast. Air temperatures in the rear half of the hurricane were thus considerably lower than those in the front half, unlike typical open-ocean hurricanes.

EB-10 had one surface-level oceanographic instrument attached to her hull and three subsurface instruments attached to her mooring cable. All instruments successfully measured temperature, salinity and pressure. Velocity measurements were not considered reliable (Withee and Johnson, 1976), and are not discussed here. EB-10's slack mooring (scope 1.25) permitted vertical motion of the subsurface instruments which was significant during the first few days after the hurricane passage. Temperature data have been corrected according to

$$
T(t)=\tilde{T}(t)+\left[Z(t)-Z_{0}\right] \partial T / \partial z,
$$

where $\tilde{T}$ is observed temperature, $Z$ is the depth of the instrument computed from measured pressure, $Z_{0}$ is the average depth during the 5-day interval before the hurricane passage, and $\partial T / \partial z$ is the local temperature gradient evaluated from hydrographic data (Table 3).

The SST at EB-10 (assumed equal to $2 \mathrm{~m}$ temperature) decreased $2^{\circ} \mathrm{C}$ as Eloise passed over (Fig. 5). There was an irregular oscillation of $0.2^{\circ} \mathrm{C}$ amplitude for roughly three days after the storm passage. The SST then stabilized and remained approximately constant for the remainder of the record. The decrease of SST that occurred during the hurricane passage thus appears to be irreversible, and was therefore probably caused by some combination of heat loss to Eloise and entrainment (vertical mixing) of cold water into the ML.

The temperature at $53 \mathrm{~m}$ depth was initially well below the SST, indicating that $53 \mathrm{~m}$ was below the base of the ML. Just after the eye of the hurricane passed over EB-10, the $53 \mathrm{~m}$ temperature began to oscillate with a near-inertial period. Within four days the $53 \mathrm{~m}$ temperature had increased to the SST value and had stabilized, indicating that the $53 \mathrm{~m}$ instrument had been engulfed by the ML. The final $53 \mathrm{~m}$ temperature was then higher than the initial $53 \mathrm{~m}$ temperature by $\sim 1.5^{\circ} \mathrm{C}$ which suggests that $\mathrm{ML}$ depth had increased by entrainment rather than by a simple free-convective adjustment (e.g., Turner, 1973, p. 304).

At 220 and $530 \mathrm{~m}$ depth (middle and lower main thermocline) the temperature oscillated in phase with the $53 \mathrm{~m}$ temperature during the first few days after the hurricane passage. The amplitude of the oscillation reached a peak nine days after the hurricane passage, and then gradually decreased, suggesting the propagation of an inertial-internal wave wake within the main thermocline.

The temperature section of Fig. $2 b$ also shows a deep response. There is a $40 \mathrm{~m}$ upwelling of isotherms centered on the storm track and in phase

TABLE 2. Buoy/hurricane encounters.

\begin{tabular}{|c|c|c|c|c|c|c|c|c|c|}
\hline \multirow{2}{*}{$\begin{array}{l}\text { Buoy/ } \\
\text { hurricane }\end{array}$} & \multirow{2}{*}{$\begin{array}{l}\text { Meteor- } \\
\text { ological } \\
\text { sensor } \\
\text { height } \\
\text { (m) }\end{array}$} & \multirow{2}{*}{$\begin{array}{l}\text { Oceanographic } \\
\text { sensor depths } \\
\text { (m) }\end{array}$} & \multicolumn{2}{|c|}{ Sampling interval (h) } & \multirow{2}{*}{$\begin{array}{l}\text { Oceanic } \\
\text { initial } \\
\text { condition }\end{array}$} & \multirow{2}{*}{$\begin{array}{c}U_{H} \\
\left(\mathrm{~m} \mathrm{~s}^{-1}\right)\end{array}$} & \multirow{2}{*}{$\begin{array}{l}\text { Maximum } \\
\text { wind speed } \\
\left(\mathrm{m} \mathrm{s}^{-1}\right)\end{array}$} & \multirow{2}{*}{$\begin{array}{l}\text { Buoy position } \\
\text { relative } \\
\text { to track } \\
(\mathrm{km})\end{array}$} & \multirow{2}{*}{$\begin{array}{l}\Delta \text { SST } \\
\left({ }^{\circ} \mathrm{C}\right)\end{array}$} \\
\hline & & & Air & Sea & & & & & \\
\hline EB-04/Eloise & 10 & 2 & 1 & 3 & known & 4 & 28 & 30 left & -3 \\
\hline EB-10/Eloise & 10 & $2,53,220,530$ & 1 & $\begin{array}{c}3,1 \text { during } \\
\text { storm passage }\end{array}$ & known & 8.5 & 35 & $\sim 0$ & -2 \\
\hline EB-15/Belle & 10 & $2,10,20$ & 3 & 3 & unknown & 13 & 31 & $\sim 0$ & -1 \\
\hline
\end{tabular}



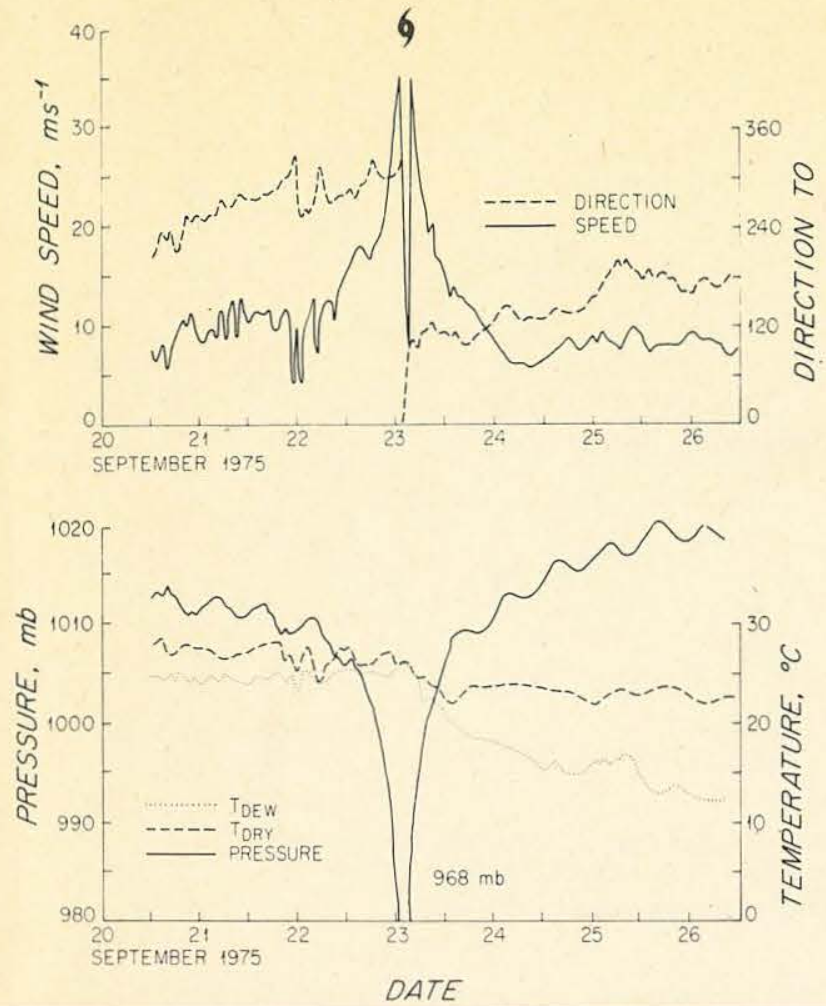

FIG. 4. Meteorological measurements from EB-10 during the passage of hurricane Eloise. Direction is given as the direction toward which the wind blows. Dates are at 0000 GMT. Data are from Withee and Johnson (1976).
TABLE 3. EB-10 temperature correction parameters.

\begin{tabular}{ccccc}
\hline \hline $\begin{array}{c}\text { Nominal } \\
\text { instrument } \\
\text { depth } \\
(\mathrm{m})\end{array}$ & $\begin{array}{c}\text { Initial } \\
\text { time-averaged } \\
\text { instrument } \\
\text { depth, } Z_{0} \\
(\mathrm{~m})\end{array}$ & $\begin{array}{c}\text { Initial } \\
\text { time-averaged } \\
\text { temperature } \\
T_{0}\left({ }^{\circ} \mathrm{C}\right)\end{array}$ & $\begin{array}{c}\text { Maximum } \\
\text { instrument } \\
\text { excursion } \\
(\mathrm{m})\end{array}$ & $\begin{array}{c}\text { Temperature } \\
\text { gradient } \\
\partial T / \partial z \\
\left({ }^{\circ} \mathrm{C} \mathrm{m}^{-1}\right)\end{array}$ \\
\hline 53 & 53 & 25.6 & 8 & $0.125 \pm 0.010^{*}$ \\
220 & 217 & 15.3 & 40 & $0.035 \pm 0.005$ \\
530 & 510 & 8.4 & 95 & $0.015 \pm 0.005$ \\
\hline
\end{tabular}

- This estimate is valid for pre-hurricane conditions, but is clearly too large for times several days after the hurricane passage.

from the base of the ML to well within the main thermocline.

\section{2) EB-04/ELoise}

Hurricane Eloise passed $\sim 30 \mathrm{~km}$ to the east of EB-04 before it reached EB-10. Eloise was changing course and strength as the strongest winds were observed at EB-04, and wind speed and direction were markedly asymmetric (Fig. 6). The SST decreased $\sim 3^{\circ} \mathrm{C}$ during the hurricane passage and the sea-surface salinity increased $\sim 3$ PPT. It is striking that the responses of SST and salinity are almost entirely out of phase.

\section{3) EB-15/BELLE}

Hurricane Belle passed directly over EB-15, moving at approximately $13 \mathrm{~m} \mathrm{~s}^{-1}$. The SST decreased

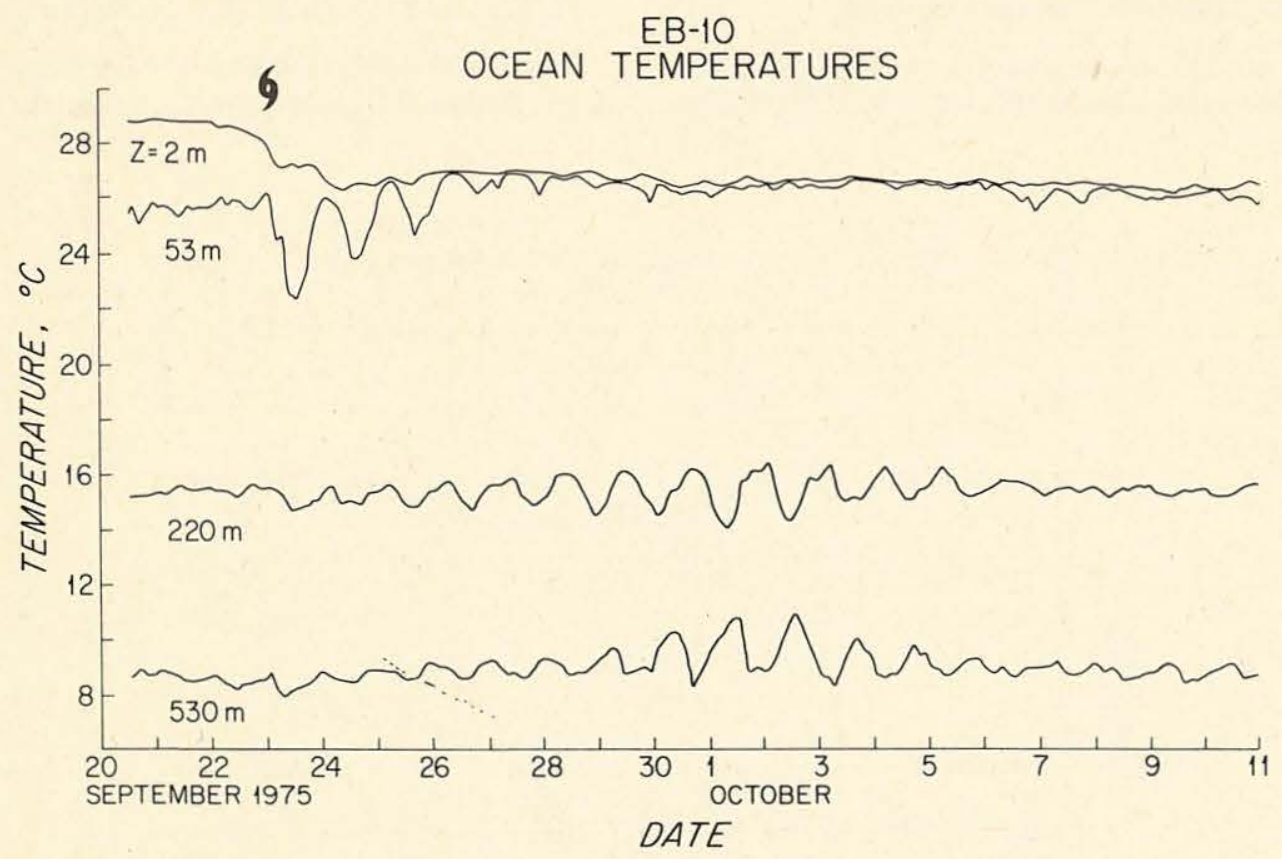

FIG. 5. Ocean temperatures from EB-10 during and after the passage of Hurricane Eloise. Nominal instrument depths are given at left. Wind speed exceeded $15 \mathrm{~m} \mathrm{~s}^{-1}$ for a period of roughly one day centered on the hurricane symbol at upper left. These data have been corrected for instrument vertical motion. Data are from Withee and Johnson (1976). 

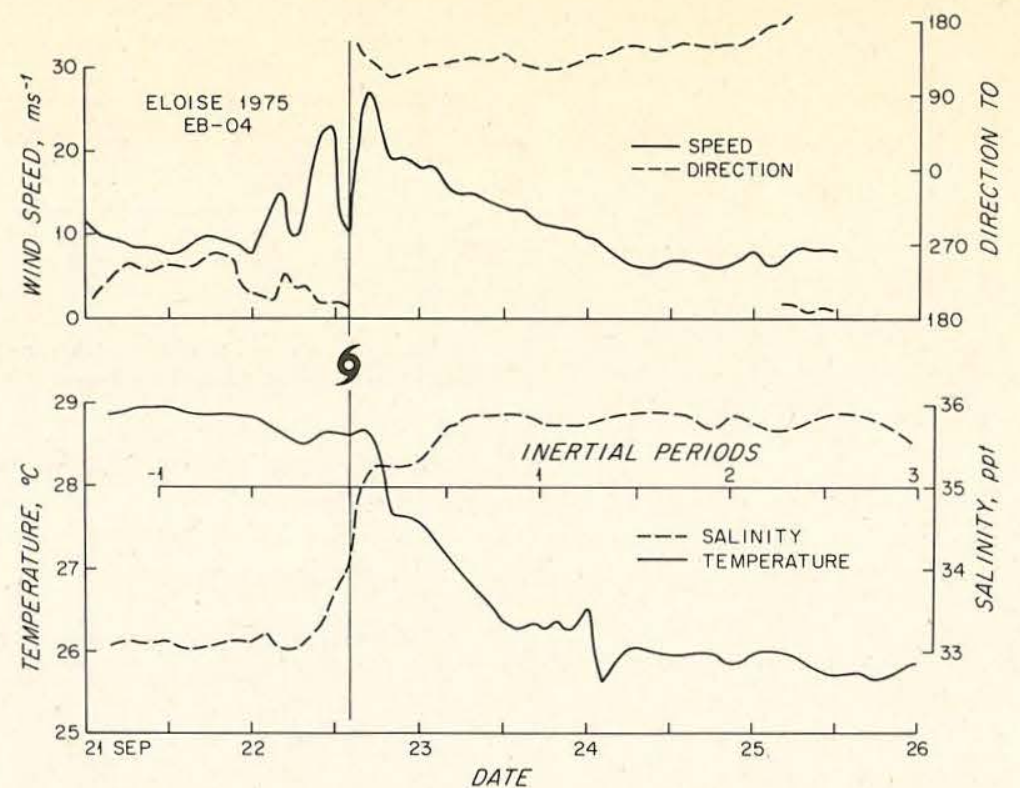

FIG. 6. Air-sea measurements (upper/lower panels) from EB-04 during the passage of Eloise. Data are from Johnson and Speer (1978). Note that almost all of the increase in sea-surface salinity occurred before the decrease in SST began.

$\sim 1^{\circ} \mathrm{C}$ during the hurricane passage, and then began a large-amplitude near-inertial oscillation (Fig. 7), which decayed to half of its initial amplitude within three days after the hurricane passage.

\section{A model of the upper ocean response}

Previous models of the oceanic response to a hurricane (O'Brien and Reid, 1967; Geisler, 1970; Ichiye,
1972; Elsberry et al., 1976; Ichiye, 1977) were reviewed by Chang and Anthes (1978) and will not be discussed here. A general review of upper ocean models was given by O'Brien et al. (1977), and Niiler and Kraus (1977).

\section{a. Scales and physical approximations}

The observations indicate the dynamics and scales that a reasonably complete model must encompass.

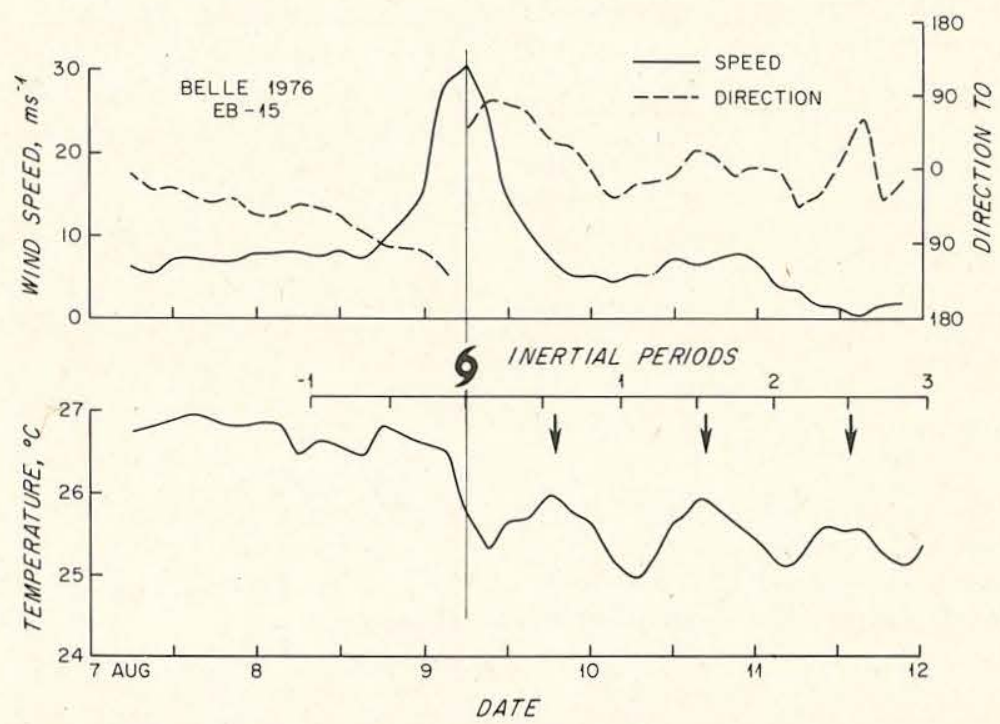

FIG. 7. Air-sea measurements (upper/lower panels) from EB-15 during the passage of Belle. Temperature is from $10 \mathrm{~m}$ depth. Data are from Johnson and Speer (1978). Note the large-amplitude, near-inertial oscillation of temperature following the hurricane passage. Arrows mark the model-predicted phase of the maxima of this oscillation (discussed in Section 5). 


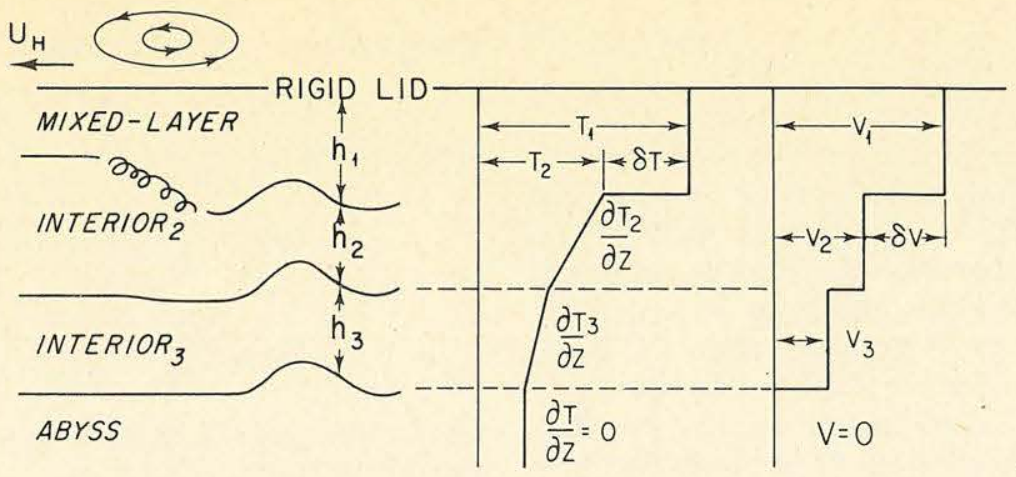

FIG. 8. Schematic vertical structure of the numerical model.

The SST response is essentially a problem of ML dynamics. This indicates a layered model (Fig. 8) whose surface ML may deepen by entrainment and absorb all of the air-sea exchanges. Two active lower layers are driven only by pressure gradients. The model must have complete horizontal dependence if it is to recover the asymmetry in the SST response. It must have horizontal resolution of $20 \mathrm{~km}$ and an extent of $500 \mathrm{~km}$ (width) to resolve adequately and contain the hurricane wind field. The dominant periodicity in the response is inertial, suggesting a time step of $\mathrm{O}\left(10^{3} \mathrm{~s}\right)$. The model must be run for a period of up to three days beyond a hurricane passage to include most of the SST response.

Physical approximations are as follows:

1) The Coriolis parameter $f$ is assumed constant, pressure is hydrostatic, the Boussinesq approximation is made throughout, and diffusive processes (other than entrainment) are excluded.

2) Density is computed from a linear equation of state,

$$
\rho=\rho_{0}[1+\alpha(T-27)+\beta(S-36)],
$$

where $\alpha=-3.3 \times 10^{-4}$ and $\beta=7.6 \times 10^{-4}$ are the appropriate thermal and haline expansion coefficients and $\rho_{0}=1.0235 \times 10^{3} \mathrm{~kg} \mathrm{~m}^{-3}$ is the reference density.

3) The sea surface is treated as a rigid lid. This conveniently excludes the barotropic mode, which is expected to be weak in the deep open ocean (Geisler, 1970), and which does not contribute to vertical shear or vertical motion.

4) The subthermocline ocean (abyss) is taken as infinitely deep and unable to sustain a pressure gradient. This allows a simple calculation of the pressure gradient in the $\mathrm{ML}$ at the expense of a small error, $\mathrm{O}\left(V_{3} / V_{1}\right)$, in $V_{1}$ and $V_{2}$ (no error in $\delta \mathbf{V}$ ).

5) The temperature and salinity in layer 2 are assumed to have (linear) depth dependence, which is essential for a realistic ML model. The velocity within layer 2, however, is assumed constant. The initial thickness of layer 2 is chosen so that after the hur- ricane passage, $h_{2} \simeq h_{1}$, consistent with a bulk treatment of the ML.

6) Vertical density gradients in layers 2 and 3 are held constant since the change due to stretching is very small during the first several days after the hurricane passage.

\section{b. Budgets}

Layer thickness may change on account of divergence of the transport within the layer, and by entrainment for layers 1 and 2;

$$
\begin{aligned}
& \frac{\partial h_{1}}{\partial t}=-\nabla \cdot\left(\mathbf{V}_{1} h_{1}\right)+W_{e}, \\
& \frac{\partial h_{2}}{\partial t}=-\nabla \cdot\left(\mathbf{V}_{2} h_{1}\right)-W_{e}, \\
& \frac{\partial h_{3}}{\partial t}=-\nabla \cdot\left(\mathbf{V}_{3} h_{3}\right),
\end{aligned}
$$

where $\mathbf{V}$ is the horizontal component of velocity and $\nabla$ the horizontal gradient operator. The entrainment velocity $W_{e} \geqslant 0$. No provision is made for the formation of a new surface ML due to a stabilizing buoyancy flux (e.g., Price, 1979b). The divergence of ML transport, $\nabla \cdot V_{1} h_{1}$, termed pumping, is much larger than the divergence within layers 2 and 3 during the first several days after hurricane passage and thus dominates the upwelling (vertical displacement of material surfaces due to advection).

Temperature $T$ and salinity $S$ are constant within the ML and have linear depth-dependence within layers 2 and 3 . There is a jump $\delta T=T_{2}-T_{1}$ across the base of the ML, where $T_{2}$ is the temperature at the top of layer 2. Heat and salt balances in the ML are

$$
\begin{aligned}
& \frac{\partial T_{1}}{\partial t}=\frac{Q}{h_{1}}-\mathbf{V}_{1} \cdot \nabla T_{1}+\frac{\delta T W_{e}}{h_{1}}, \\
& \frac{\partial S_{1}}{\partial t}=\frac{S_{1} F}{h_{1}}-\mathbf{V}_{1} \cdot \nabla S_{1}+\frac{\delta S W_{e}}{h_{1}} .
\end{aligned}
$$


The heat flux $Q=Q_{S}+Q_{L}+R$ is the sum of sensible, latent and radiative heat exchange across the sea surface, and $F$ is the mass flux, equal to evaporation minus precipitation. The radiative heat flux $R$ was measured by some of the buoys and can always be computed given cloud cover. Precipitation is taken as given, and evaporation may be computed from $Q_{L}$. Calculation of $Q_{L}$ and $Q_{S}$ is discussed below. Note that $Q$ has kinematic units, ${ }^{\circ} \mathrm{C} \mathrm{m} \mathrm{s}^{-1}$ $\approx 1.01 \times 10^{2} \mathrm{cal} \mathrm{cm}^{-2} \mathrm{~s}^{-1}=4.20 \times 10^{6} \mathrm{~W} \mathrm{~m}^{-2}$.

The term $\delta T W_{e}$ is called the entrainment heat flux and is the bulk representation of the turbulent heat flux which occurs when the ML entrains fluid from layer 2. In the usual case where the ML is warmer than the fluid beneath and $\delta T<0$, the entrainment flux acts to cool the ML. Similar entrainment-flux terms appear in other ML budgets and are often important. Iverson (1977) and Imberger et al. (1979) have noted that hurricane-forced entrainment of nutrients into the late-summer photic zone can cause a major increase in basic productivity.

To compute $\delta T$ and $\delta S$ we must keep track of $T_{2}$ and $S_{2}$, i.e.,

$$
\begin{aligned}
& \frac{\partial T_{2}}{\partial t}=-\mathbf{V}_{2} \cdot \nabla T_{2}+W_{e} \frac{\partial T_{2}}{\partial z} \\
& \frac{\partial S_{2}}{\partial t}=-\mathbf{V}_{2} \cdot \nabla S_{2}+W_{e} \frac{\partial S_{2}}{\partial z},
\end{aligned}
$$

where $\partial T_{2} / \partial z$ is understood to be the vertical gradient of $T$ within layer 2 .

Momentum balances for the layers are

$$
\begin{aligned}
\frac{\partial \mathbf{V}_{1}}{\partial t}=-\mathbf{f} \times \mathbf{V}_{1} & +\frac{\tau}{h_{1}} \\
& -\mathbf{V}_{1} \cdot \nabla \mathbf{V}_{1}-\nabla P_{1}+\frac{\delta \mathbf{V} W_{e}}{h_{1}}, \\
\frac{\partial \mathbf{V}_{2}}{\partial t}= & -\mathbf{f} \times \mathbf{V}_{2}-\mathbf{V}_{2} \cdot \nabla \mathbf{V}_{2}-\nabla P_{2}, \\
\frac{\partial \mathbf{V}_{3}}{\partial t}= & -\mathbf{f} \times \mathbf{V}_{3}-\mathbf{V}_{3} \cdot \nabla \mathbf{V}_{3}-\nabla P_{3},
\end{aligned}
$$

where $\mathbf{f}$ is the Coriolis parameter times the vertical unit vector, $\tau$ is wind stress, and $P$ the hydrostatic pressure perturbation caused by upwelling and entrainment ( $\tau$ and $P$ have kinematic units). Given that $\nabla P=0$ at the base of layer 3 and knowing the density and thickness of the overlying layers, the pressure gradients are

$$
\begin{aligned}
& \nabla P_{1}=-g\left(1 / 2 h_{1} \nabla \rho_{1}+h_{2} \nabla \rho_{2}\right. \\
& \left.+h_{3} \nabla \rho_{3}-\delta \rho \nabla h_{1}\right) / \rho_{0}, \\
& \nabla P_{2}=-g\left(1 / 2 h_{2} \nabla \rho_{2}+h_{3} \nabla \rho_{3}\right) / \rho_{0}, \\
& \nabla P_{3}=-g 1 / 2 h_{3} \nabla \rho_{3} / \rho_{0} \text {. }
\end{aligned}
$$

The horizontal density gradient in the ML is simply

$$
\nabla \rho_{1}=\rho_{0}\left(\alpha \nabla T_{1}+\beta \nabla S_{1}\right),
$$

and in the lower layers

$$
\begin{aligned}
& \nabla \rho_{2}=\frac{\partial \rho_{2}}{\partial z} \nabla\left(h_{1}+h_{2}\right), \\
& \nabla \rho_{3}=\frac{\partial \rho_{3}}{\partial z} \nabla\left(h_{1}+h_{2}+h_{3}\right),
\end{aligned}
$$

where the vertical density gradients are given as part of the initial condition.

\section{c. Turbulent-flux parameterizations}

Two key turbulent transfer processes, entrainment and air-sea heat and momentum exchange, occur on time and space scales very much shorter than those resolved in the model and must be parameterized. The success of the model depends on the success of these parameterizations and their consequences will be discussed in some detail in Sections 5 and 6.

The air-sea sensible and latent heat fluxes are calculated from model-computed SST and observed meteorological parameters with conventional bulk aerodynamic formulas:

$$
\begin{aligned}
Q_{S} & =\rho_{*} C_{Q} U_{10}\left(T_{10}-\mathrm{SST}\right) B, \\
Q_{L} & =\rho_{*} C_{Q} U_{10}\left(q_{10}-q_{s s}\right) K,
\end{aligned}
$$

where

$\rho_{*} \quad$ density of air divided by density of seawater

$C_{Q} \quad$ bulk transfer coefficient, $=1.3 \times 10^{-3}$

$U_{10} \quad$ wind speed at $10 \mathrm{~m}$ height

$T_{10} \quad$ air temperature at $10 \mathrm{~m}$ height

$B$ heat capacity of air divided by heat capacity of seawater

$q_{10, s s}$ specific humidity at $10 \mathrm{~m}$ height, and at the sea surface assuming saturation at the sea surface temperature

$K \quad$ latent heat of vaporization divided by the heat capacity of seawater.

Wind stress is computed in a similar way,

$$
\boldsymbol{\tau}=\rho_{*} C_{D} U_{10} \mathbf{U}_{10},
$$

where the drag coefficient

$$
C_{D}=\left(0.73+0.069 U_{10}\right) \times 10^{-3}
$$

is Garrett's (1977) composite form. It is encouraging to note that Miller (1964) computed a very similar wind-speed dependent $C_{D}$ from direct observations of hurricane winds.

To finish the model we must parameterize entrainment in terms of the resolved variables. The parameterization used here was calculated (Price, 1979a) from the laboratory experimental data on stressdriven entrainment of Kato and Phillips (1969) and Kantha et al. (1978), 


$$
E=\frac{W_{e}}{\delta V}= \begin{cases}5 \times 10^{-4} R_{V}^{-4}, & \text { if } R_{V} \leqslant 1 \\ 0, & \text { if } R_{V}>1,\end{cases}
$$

where $R_{V}=g \delta \rho h_{1} / \rho_{0} \delta \mathrm{V}^{2}$ is a bulk Richardson number. There were no reliable data in the range $R_{V}>1$. Because $E$ is already very small at $R_{V}=1, E$ is assumed to vanish if $R_{v}>1$.

Two qualitative features of (10) deserve note. First, under storm conditions $E$ varies primarily on account of variation in the shear $\delta \mathrm{V}$ which is strongly dominated by $V_{1}$. Hence this parameterization will predict that entrainment will be large where $V_{1}$ is large. Second, the rate of decrease of $E$ with $R_{y}$ is sufficiently steep that (10) is similar to a critical $R_{V}$ closure (Pollard et al., 1973) where the critical value $R_{V} \approx 0.6$ (Price et al., 1978).

\section{d. Implementation}

The equations are integrated numerically as an initial value problem. The initial condition is the initial $T, S$ profiles; $V$ is assumed zero. The initial ocean is assumed to be laterally homogeneous. The hurricane wind and temperature fields are taken as

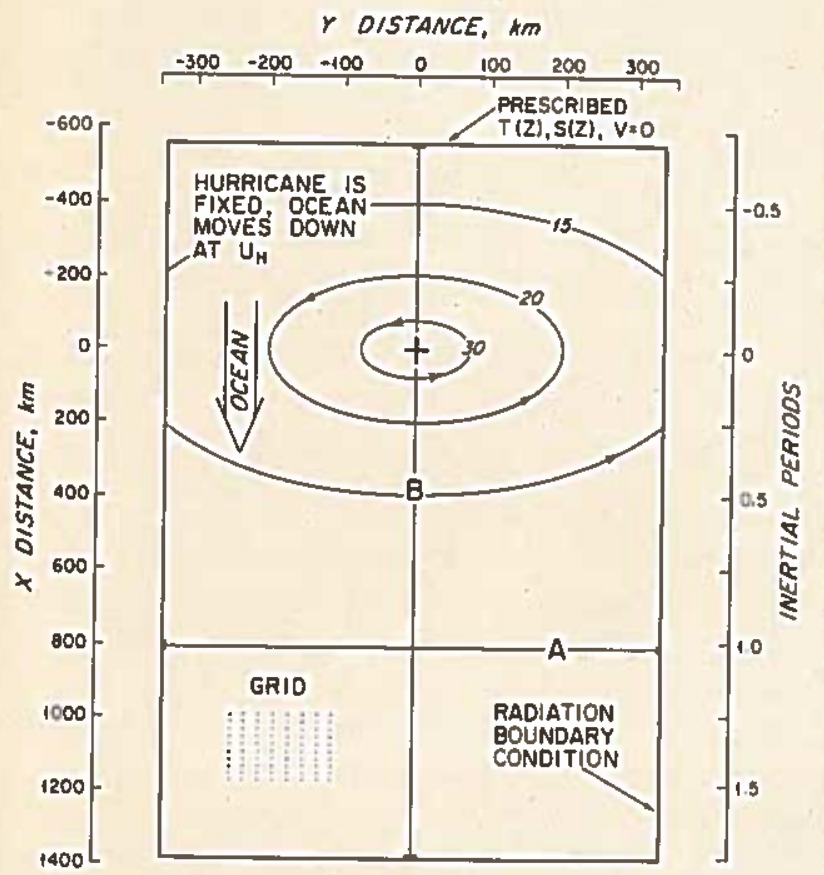

FIG. 9. Schematic plan view of the numerical model. The view is from the frame of a moving hurricane that is centered at $(x, y)$ $=(0,0)$. Wind speed contours are shown in $\mathrm{m} \mathrm{s}^{-1}$. The ocean appears to move down the grid at a rate $U_{H}$. Because $U_{H}$ is constant, time and $r$-distance are proportional. This and subsequent similar figures are distorted in the ratio $x / y=2: 1$. In practice, the grid extends to $x=-800 \mathrm{~km}$ in order to encompass the strongest winds of the hurricane. The solution is sectioned along $A$ to show the cross-track profile; the solution seetioned along $B$ is equivalent to a time series observed at a fixed buoy run over by the hurricane eye.

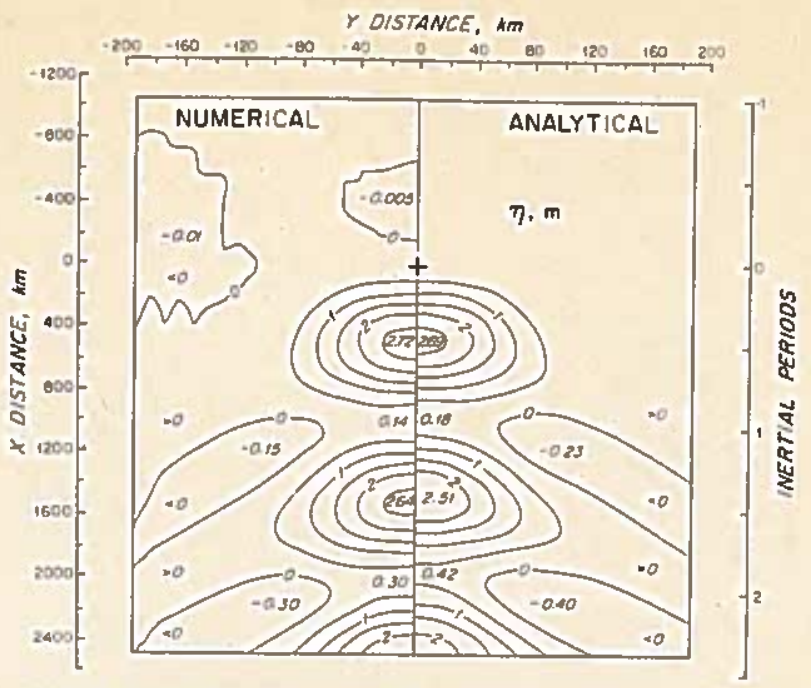

FIG. 10. Upwelling computed by the numerical model (left side) and from Geisler's (1970) analytical solution (right side). Paramelers were chosen to match Geisler's Fig. 3. Note that the two patches contoured in the upper portion of the numerical solution represent very small values of upwelling. The generally good agreement between these two solutions is taken as evidence that the numerical solution is approximately correct.

given (Fig. 9), and are centered on $(x, y)=(0,0)$. The motion of the hurricane is implemented by advecting the ocean down the grid at a rate $U_{H}$. The time step $\Delta t$ is chosen so that this advection will be computed exactly; $\Delta t=\Delta x / m U_{H}$, where $m$ is the smallest integer that gives $\Delta t \leqslant 2 \times 10^{3} \mathrm{~s}$. The ocean is moved down the grid one row after every $m$ time steps and the first row of grid points is updated with the ocean initial condition. A steady-state solution is reached soon after a particle which started off on the first row has been advected out of the grid.

Space derivatives are estimated with a second-order centered form, and time-stepping is carried out using the three-time-level, two-step, leapfrog trapezoidal method (Roache, 1976, p, 91). A radiation boundary condition is applied on the sides of the grid to minimize reflection of energy back into the interior.

The numerics that contribute to internal-wave dynamics may be tested by comparison with the analytical solutions of Geisler (1970) and Ichiye (1972), who computed the linear response of an open, two-layer ocean to a steadily moving stress curl (Fig. 10). The discrepancies are acceptable-roughly $5 \%$ of the maximum values.

The tendency for ML variables includes a very important entrainment-flux term. Because the entrainment parameterization (10) is highly nonlinear, the entrainment terms are estimated using a trapezoidal method with a smaller time step $0.2 \Delta t$. A check of the entrainment calculations may be made by comparing the numerical solutions with the result for quasi-steady entrainment (Price, 1979a) 
TABle 4. EB-10/Eloise ocean initial condition.

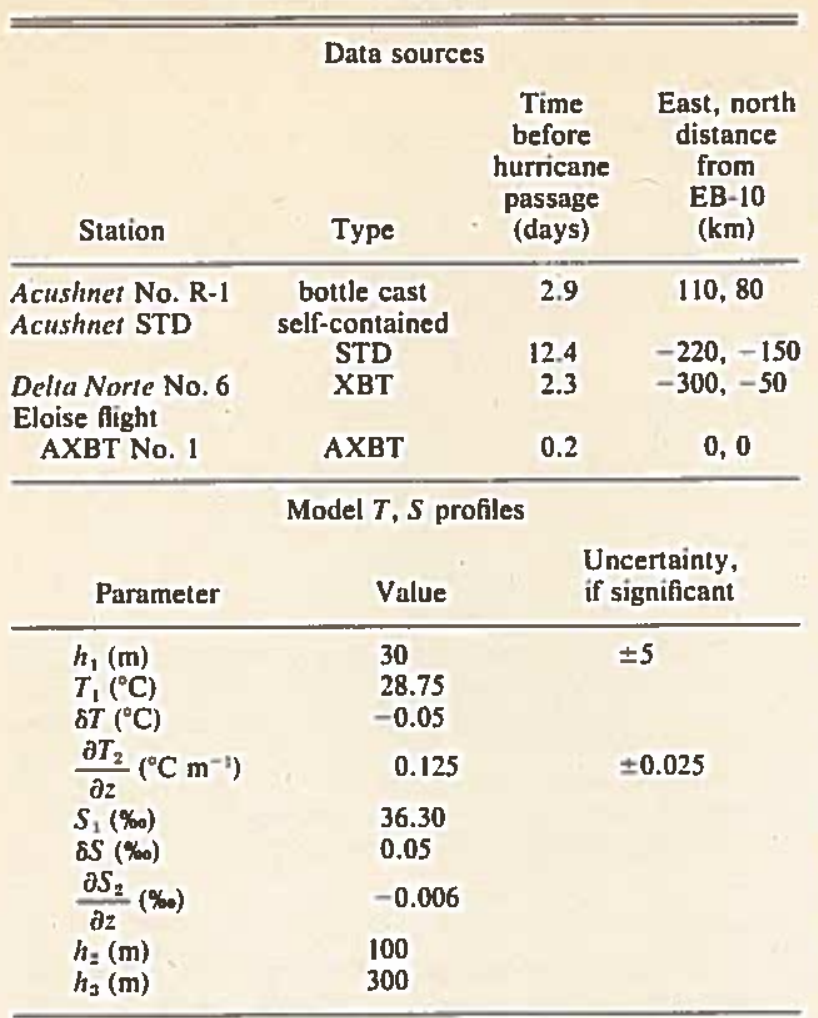

$$
W_{\mathrm{r}} / \tau^{\mathrm{t} / 2}=n R_{\mathrm{r}}{ }^{1 / 2} R_{\mathrm{r}}{ }^{-1 / 2},
$$

where $n=1 / 2$ for a linearly stratified fluid, and $n=1$ for a two-layer stratified fluid, and where $R_{7}=(g h \delta \rho) /$ $\left(\rho_{i v} \tau\right)$ is the external bulk Richardson number. The model solutions match (11) to within a few percent, indicating that the model conserves density and momentum correctly during entrainment.

\section{Specification of the EB-10/Eloise case}

To simulate a given case we must specify the oceanic initial condition and the two-dimensional hurricane surface wind and temperature fields. These rather demanding requirements can be satisfied only for the EB-10/Eloise case. (The non-steady nature of Eloise at EB-04 precludes any simple specification of the wind fields. There is apparently no source of information on the oceanic initial condition for the EB-15/Belle case.)

\section{a. Oceanic initial condition}

Several ship-of-opportunity hydrographic stations were taken in the north-central Gulf of Mexico during the two-week period before the passage of Eloise, and were made available through NODC (Table 4). The EB-10 temperature and salinity observations are used as benchmarks in constructing the initial model $T, S$ profiles (Fig. 11). The hydrographic observa-

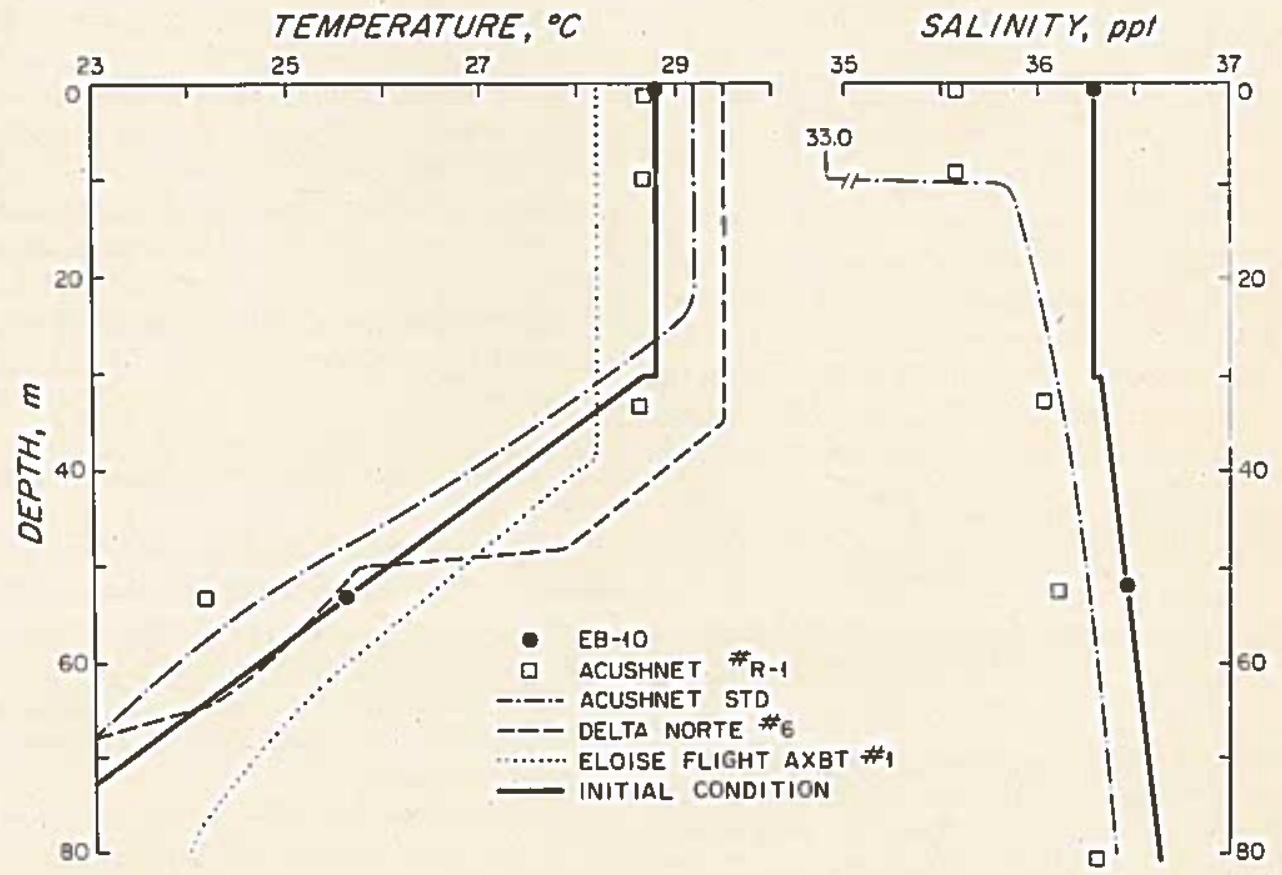

FiG. 11. Temperature and salinity profiles observed in the north-central Gulf of Mexico before the passage of Eloise. EB-10 data points are averages over the 5-day period preceding the passage of Eloise. The AXBT was taken while Eloise was over EB-10 and the ML depth and temperature are not representative of the undisturbed initial condition. The heavy solid line is the initial condition used in the simulation of the EB-10/Eloise case. Note that the Acushnet STD salinity profile which was made very near EB-04 showed a $10 \mathrm{~m}$ thick surface layer of anomalously fresh water. The salinity data from EB-10 do not show this fresh layer. 


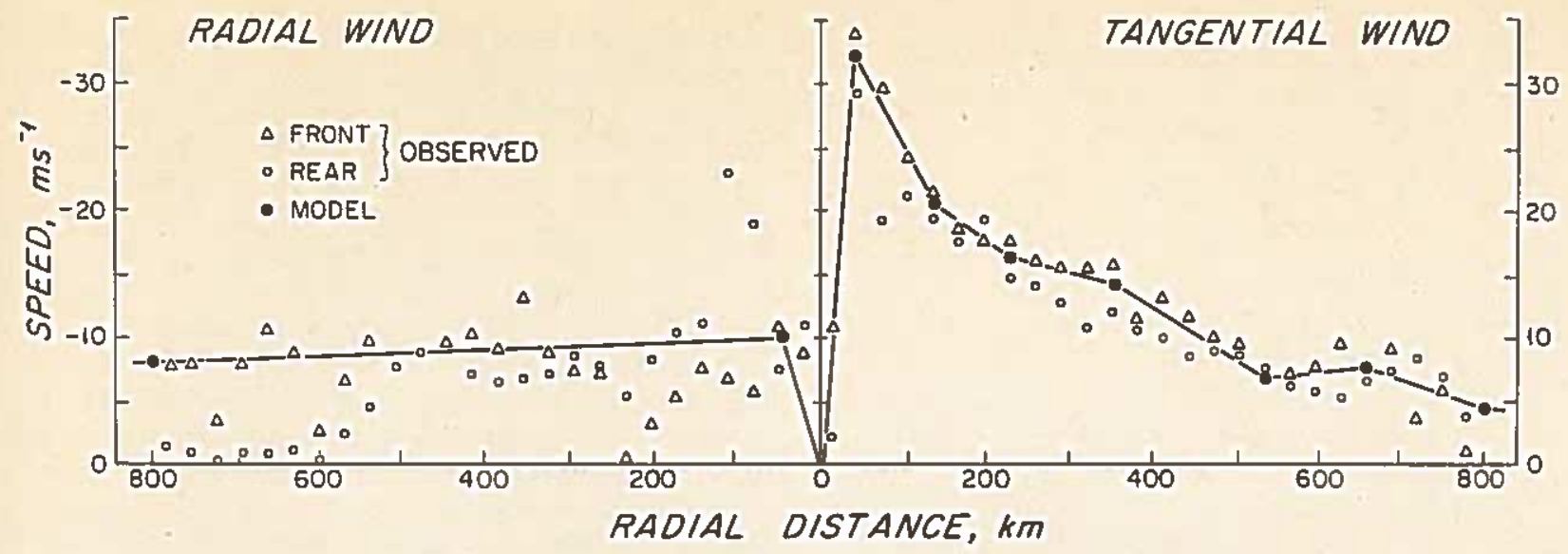

F1G. 12. Radial and tangential wind-speed radial profiles computed from the EB-10 wind data (points), and the model of the hurricane used in the simulation of the EB-10/Eloise event (solid line).

tions are used to set the initial ML depth and the temperature and salinity gradients below the ML. The model profile includes a very small jump across the base of the ML so that $R_{1}$, will not be vanishingly small during the first time step of the numerical integration. Uncertainties are estimated for the two most important parameters, $h_{1}$ and $\partial T_{2} / \partial z$. The effect of possible error in setting the initial condition will be computed from the results of sensitivity tests discussed in Section 7.

The velocity initial condition is taken to be a state of rest. Weather conditions were fair during the week preceding the hurricane, and it is very unlikely that there were initial wind-driven motions of magnitude competitive with those generated by Eloise.

\section{b. Model hurricane}

Radial and tangential wind components of Eloise were computed from the observed wind speed and direction by performing a time-to-space conversion (Fig. 12). It was assumed that Eloise passed directly over EB-10, moving steadily at $8.5 \mathrm{~m} \mathrm{~s}^{-1}$ on a course of $40^{\circ} \mathrm{T}$. The most symmetric radial wind profile resulted from assuming that none of the hurricane translation velocity added to the observed surface winds. The model hurricane is thus symmetric.

A piecewise-continuous model of the hurricane was constructed by choosing several points which characterize the radial profiles. The model winds are thus considerably smoother than the observed winds. The effect of neglected high-frequency structure may be assessed by comparing the ML transports computed from a local momentum balance ( $h_{1}$ is constant),

$$
\frac{\partial\left(V_{1} h_{1}\right)}{\partial t}=-\mathbf{f} \times V_{1} h_{1}+\tau
$$

using the directly observed hurricane wind, and the model hurricane wind (Fig. 13). The model
$V_{1} h_{1}$ lags the observed $V_{1} h_{1}$ by $\sim 0.1$ IP (Inertial Periods), but has a very similar maximum amplitude. The relatively smooth model hurricane thus appears to be a satisfactory representation of Eloise.

The temperature fields of Eloise were markedly asymmetric, as noted earlier, and must be represented by a function of $x$ (Fig. 14). Details of the air-temperature specification are not important because the air-sea heat exchange is a relatively small term in the ML heat budget (shown below).

\section{Overview of the response}

\section{a. Rightward bias}

The response of the ML velocity is strongly biased to the right side of the hurricane track (Fig. 15). This bias occurs because (in the ocean frame) the windstress vector turns clockwise in time on the right side of the track and anticlockwise on the left side of the track (Fig. 16). For typical hurricane dimensions and translation speeds the rate of turning of

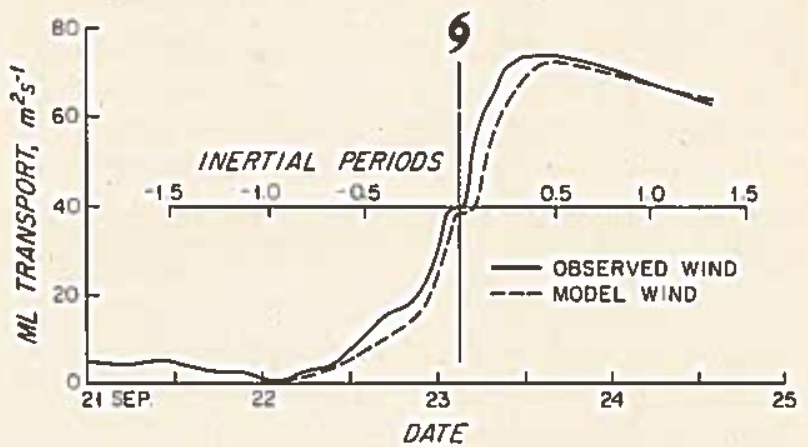

FIG. 13. ML transport $V_{1} h_{1}$ computed from the directly observed winds of Eloise (solid line) and from the model hurricane of Fig. 12 (dashed line). The generally reasonable agreement between these two curves is taken as evidence that the highfrequency fluctuations in the wind field do not have a significant effect on the net air-sea momentum transfer. 


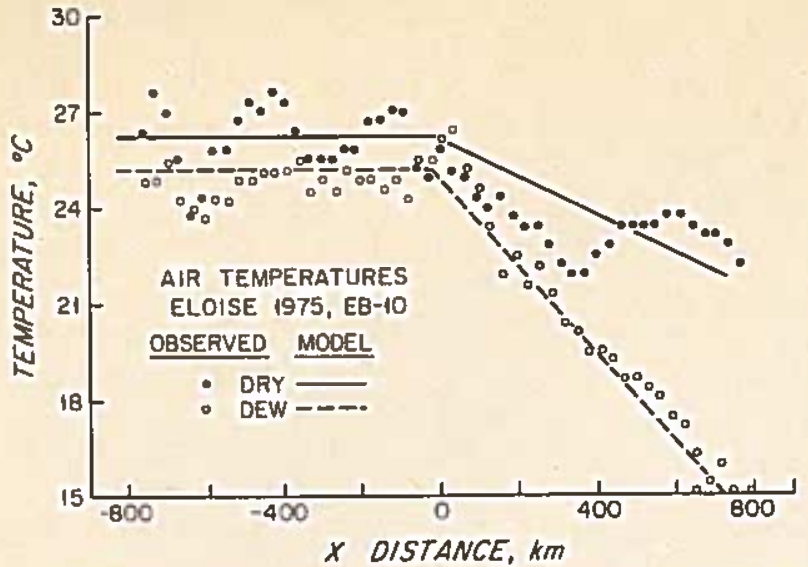

FIG. 14. Dry-bulb and dew-point temperatures from the EB-10 meteorological data. The model of these temperature fields (solid and dashed lines) is $x$ dependent.

the stress vector on the right side is comparable to the turning rate of an inertial motion. Hence there is a near-resonant coupling of the wind stress and the wind-driven near-inertial rotating $M L$ velocity.
This rightward bias in the velocity response is clearly not model dependent; it was described by Chang and Anthes (1978) and noted by Gonella (1972).

The SST response in the model shows a corresponding rightward bias (Fig. 15b). The maximum SST response, $-3.1^{\circ} \mathrm{C}$, occurs to the right of the track at $y=+60 \mathrm{~km}$; the response at $y=-60 \mathrm{~km}$ is $-0.8^{\circ} \mathrm{C}$, or roughly a factor of 4 smaller (more easily seen in Fig. 17). This is comparable to the rightward bias observed in the SST response to hurricanes Ella and Tess (Figs. 1 and 2). The bias in SST response is model dependent; it follows from the velocity bias because the parameterization of entrainment (10) depends upon velocity shear, and because the entrainment heat flux dominates the ML heat budget (discussed below).

Previous investigators have argued that the rightward bias in SST is due to the occurrence of stronger winds on the right side of a hurricane. We can test this conjecture by imposing a plausible asymmetry on the symmetric model of hurricane Eloise. Cardone et al. (1977) suggest that about half the translation velocity may add to the $10 \mathrm{~m}$ winds of a symmetric hurricane, $\vec{U}_{10}=\mathbf{U}_{10}-\mathbf{U}_{H} / 2$. This causes a substan-
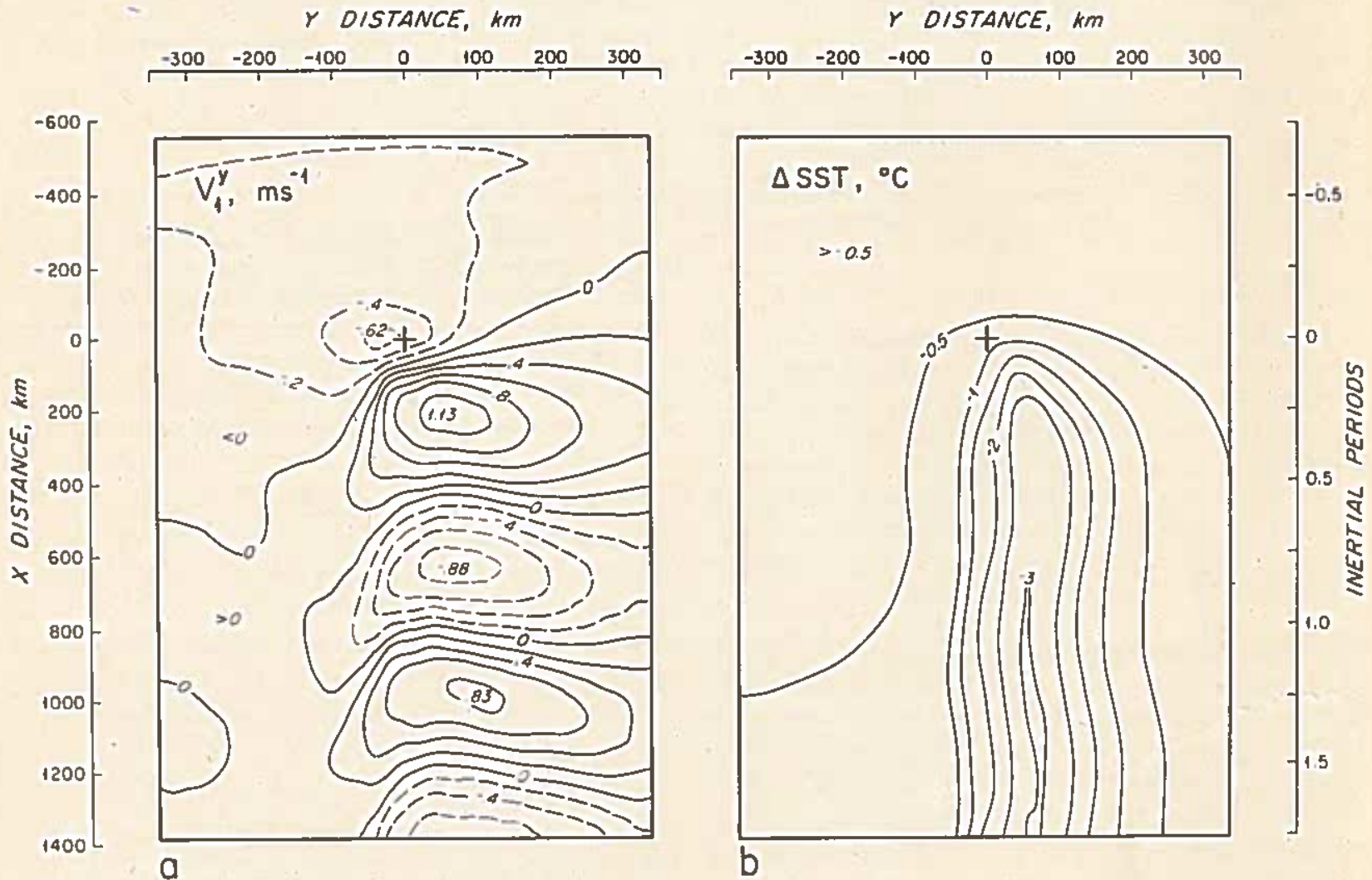

Fig, 15a. Plan view of the model-predicted $y$ component of ML velocity, $V_{1}^{\nu}\left(m \mathrm{~s}^{-1}\right)$. Contour interval is $0.2 \mathrm{~m} \mathrm{~s} \mathrm{~s}^{-1}$, negative values are dashed. The $x$ component of velocity is very similar, but lags by approximately one-quarter inertial period. The size and position of the hurricane are as shown in Fig. 9. The hurricane track runs down the center of these figures.

FIG. Isb. The SST response shown as the change in sea surface temperature from the initial condition, $\Delta$ SST $\left({ }^{\circ} \mathrm{C}\right)$. Contour interval is $0.5^{\circ} \mathrm{C}$. Note that the largest velocities and the greatest SST response occur $\sim 60 \mathrm{~km}$ to the right of center. 
$Y$ OISTANCE, $\mathrm{km}$
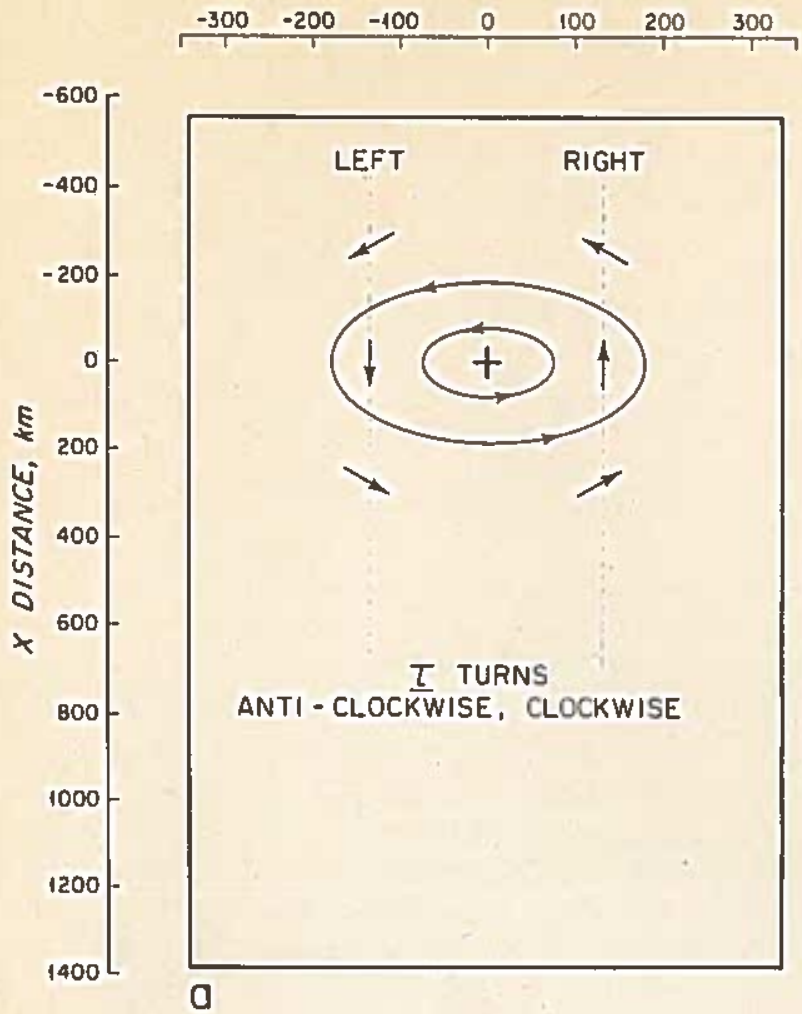

$r$ DISTANCE, $\mathrm{km}$

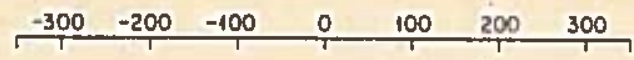

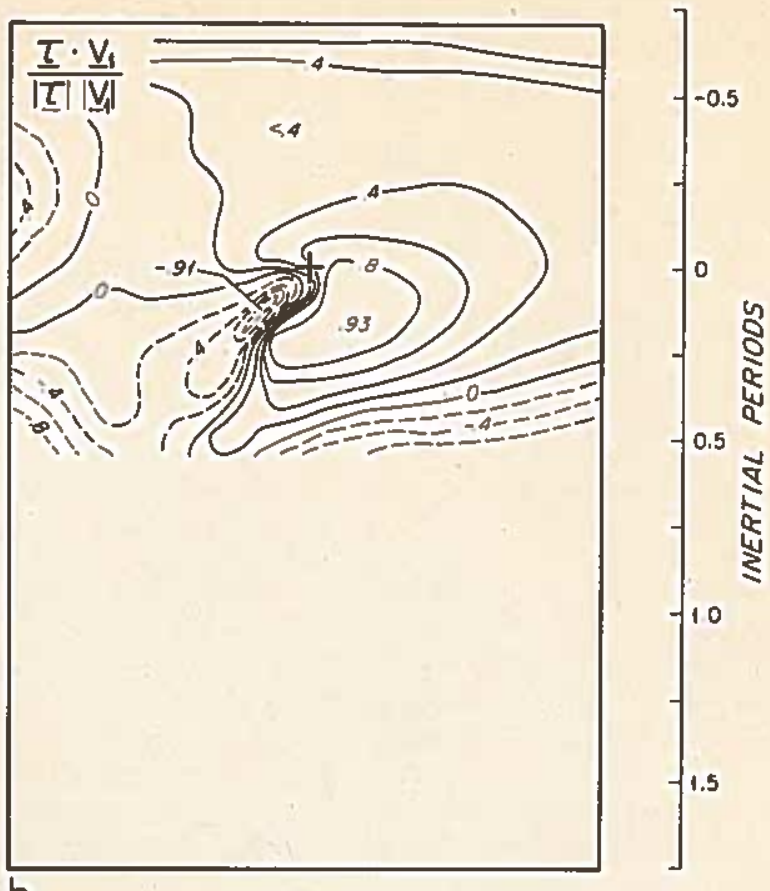

FIG. 16a. A schematic that shows the rotation of a wind-stress vector on the left and right side of a moying cyclonic stress pattern. Stress turns clockwise on the right side and thus is well coupled to inertial currents (Northern Hemisphere). The same asymmetry occurs with an anticyclonic stress pattern.

FIG. 16b. The cosine of the angle between the wind stress and the ML velocity. Contour interval is 0.2 . This is a measure of how efficiently the wind stress is working to increase the ML kinetic energy.

tial (roughly factor-of-2) asymmetry in the wind-stress magnitude and somewhat enhances the asymmetry in the SST response (Fig. 17). It is clear, however, that in this model the asymmetry in the SST response is due mainly to the asymmetry in the turning direction of the wind-stress vector.

An entrainment parameterization of the form $W_{\mathrm{e}} / U_{*} \sim R_{\mathrm{f}}{ }^{-1}$ yields a symmetric SST response to a symmetric storm (Chang and Anthes, 1978). With the asymmetric storm noted above, $\Delta$ SST has a rightward bias of about 1.6 , somewhat less than observed.

\section{b. Horizontal advection of SST}

The $y$-component of velocity in the ML combined with the strong $y$-gradients in $\triangle$ SST cause significant horizontal advection of SST. From the frame of the hurricane, this appears as a standing-wavelike perturbation of SST (Fig. 15b) which has a wavelength $\approx U_{n} \times 0.95 \mathrm{IP}(\approx 750 \mathrm{~km}$ in this case $)$. The amplitude of the horizontal displacement is $\approx 20 \mathrm{~km}$ near the point of $\Delta S_{S T} T_{\max }$. At a buoy fixed in the ocean, the signature of this horizontal advection is a near-inertial oscillation of SST. This oscillation is pronounced in the simulation of the EB-10/Eloise case (see Fig. 23), but is not so clearly present in the EB-10 data.

A similar SST oscillation is present in the EB-15 data (Fig. 7). The phase of the oscillation observed at EB-15 is essentially as predicted by the model; the first maxima occurs at $t \approx 0.6$ IP at the end of the first positive (rightward) half cycle of $V_{t}$. Subsequent maxima follow at intervals of $\approx 0.95$ IP. The amplitude of the oscillation observed at EB-15 decays to half of its initial value within 3 IP, probably on account of dispersion of the ML velocity (rather than a decrease in the gradjent).

The phase and magnitude of the horizontal advection depend on $y$-position. The $y$ component of the ML current has roughly the same phase at all $y$ (Fig. 15a); however, the temperature gradient $\partial$ SST/ $\partial y$ changes sign with $y$. A buoy at $y=+200 \mathrm{~km}$ would observe horizontal advection that has the antiphase of that observed at $y=0$, while a buoy at $y=+60 \mathrm{~km}$ (near the point of maximum SST response) would observe very weak horizontal advection with twice the near-inertial frequency. 


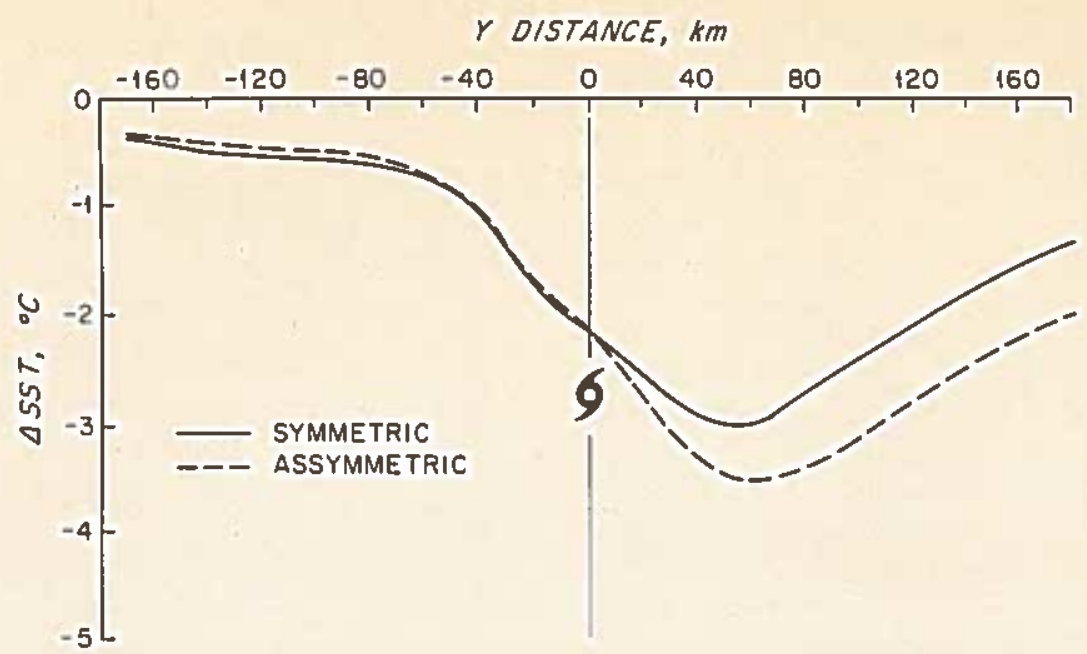

Fig. 17. Cross-track profile (section A of Fig. 9) of SST response from the EB-10/ Eloise simulation that had a symmetric hurricane (solid line), and from an otherwise similar case driven with an asymmetric hurricane (dashed line).

c. Upwelling, presstire gradients and the velocity response in the interior

It is apparent from Fig. 15a that there is substantial divergence in the $\mathrm{ML}$ velocity field. The term $\partial V y / \partial y$ dominates the divergence, and one can easily estimate the phase of the resultant pumping (Fig. 18b) and upwelling (Fig. 19b). A slice across the track would show an upwelled dome in isotherms of roughly $200 \mathrm{~km}$ width centered on the track (cf.
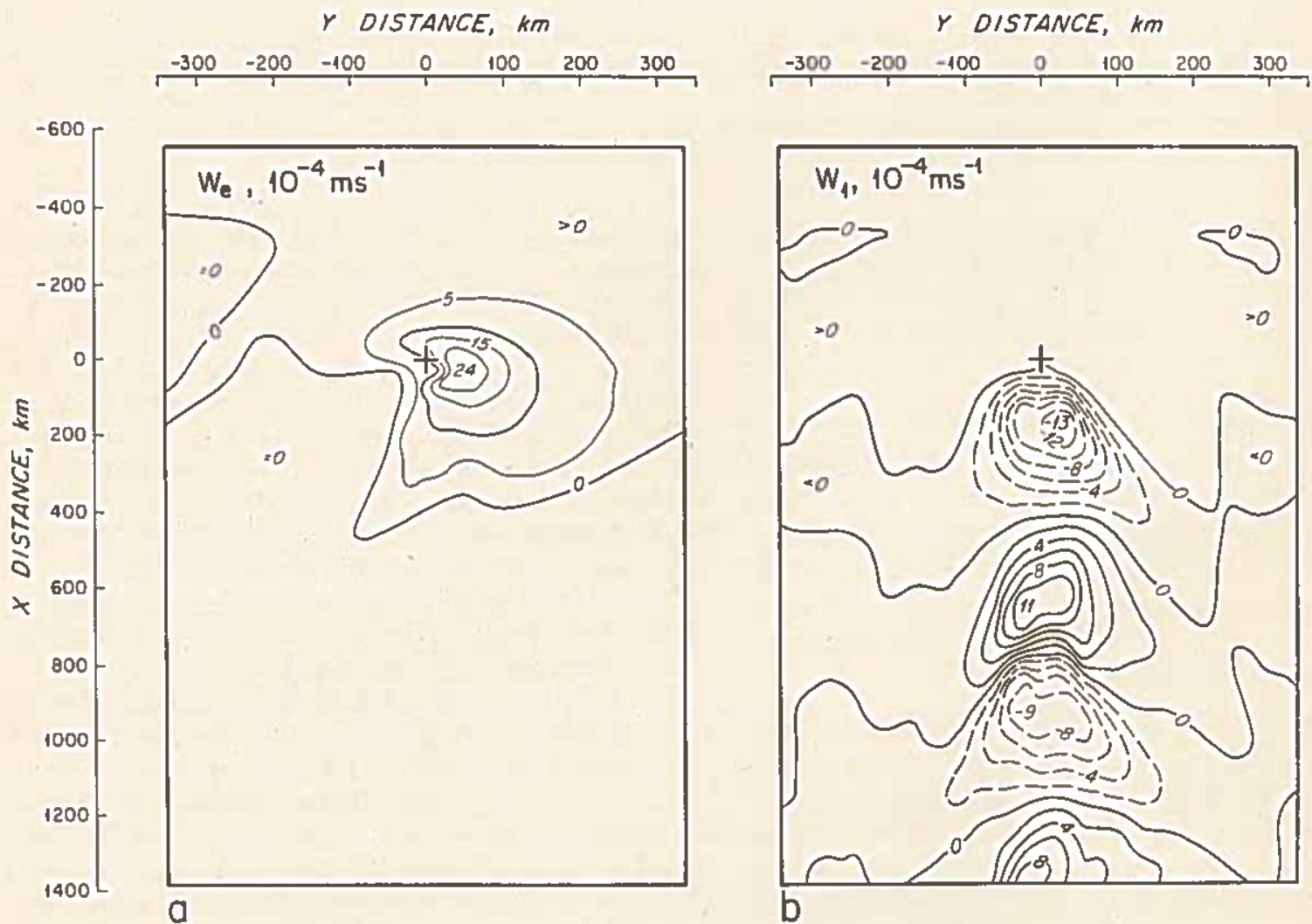

FIG. 18a. Entrainment velocity for the EB-10/Eloise case. Contour interval is $5 \times 10^{-4} \mathrm{~m} \mathrm{~s}^{-1}$.

Fig. 18b. Pumping. Contour interval is $2 \times 10^{-1} \mathrm{~m} \mathrm{~s}^{-1}$. Negative values indicate upward motion, which tends to reduce $h_{\mathrm{L}}$. 

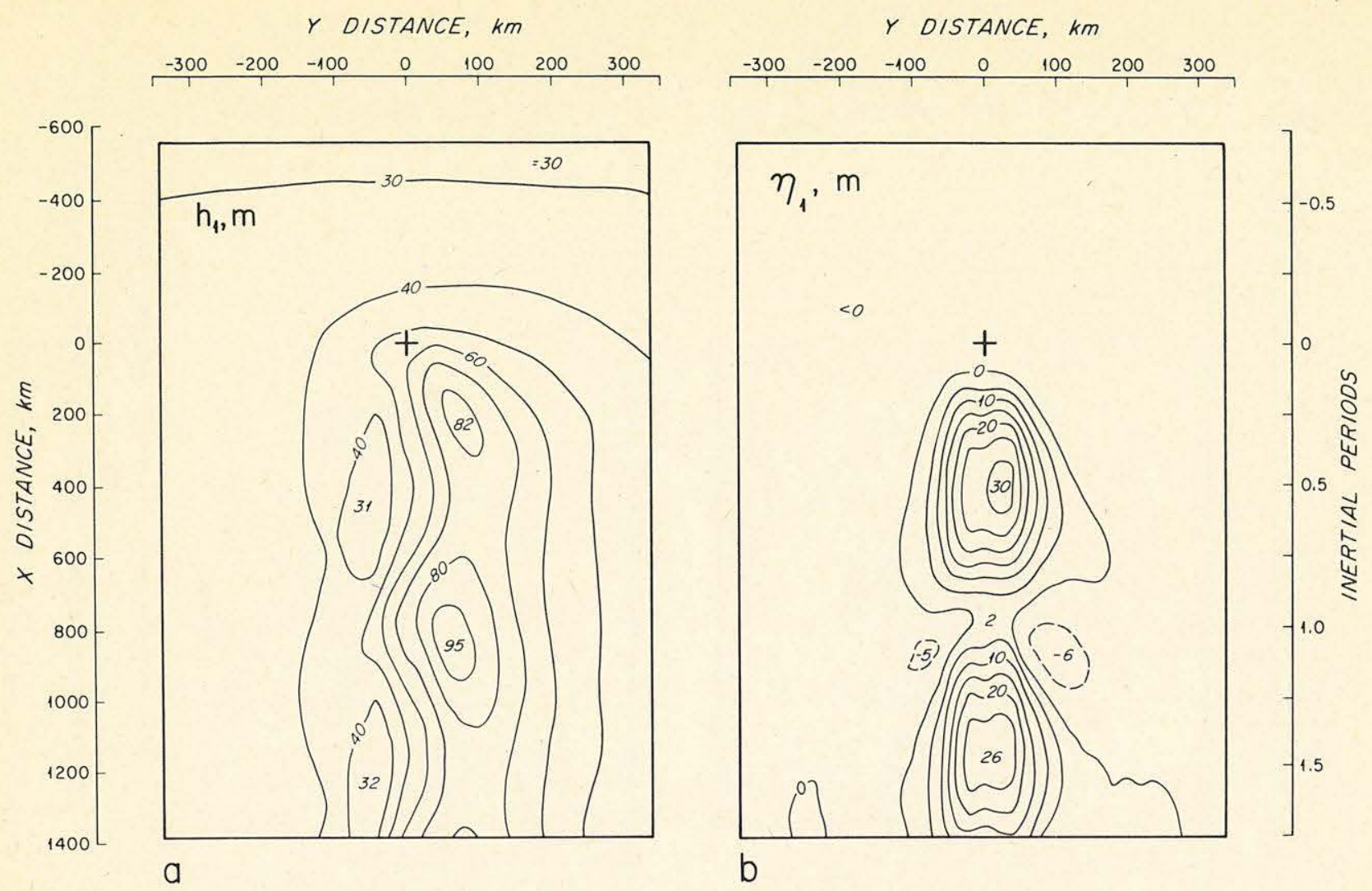

FIG. 19a. ML depth for the EB-10/Eloise case. Contour interval is $10 \mathrm{~m}$.

FIG. 19b. Upwelling just below the base of the ML. Contour interval is $5 \mathrm{~m}$.

the Tess section, Fig. 2b). The amplitude of the upwelling depends on the distance (or equivalent time) from the storm center, and could be anything from a few meters to $30 \mathrm{~m}$ in the case of Hurricane Eloise.

There are two dynamical consequences of the upwelling:

1) The first half of the upwelling cycle is upward and thus tends to cause the ML thickness to decrease. If this occurs while the ML is entraining, then entrainment will be enhanced. A comparison of $W_{e}$ with $W_{1}$ (cf. Figs. 18a and 18b) suggests that there is little overlap of these processes for the EB10/Eloise case, and little enhancement of entrainment. There is significant enhancement, however, for slowly moving hurricanes (discussed in Section 7).

2) Upwelling sets up a time-dependent pressure gradient which couples the ML with the interior and causes the ML velocity to rotate $\sim 5 \%$ faster than that in a free inertial motion. The ML velocity decays by dispersion at a rate $-V_{1} \partial t / \partial V_{1}=5-10$ days (Fig. 15a); the velocity in the interior accelerates, and by 2 IP has reached $0.3 \mathrm{~m} \mathrm{~s}^{-1}$ in layer 2 (Fig. 20a). The velocity in layer 3 (not shown) is about one-third as large.
The dispersion time is large compared to that over which entrainment occurs, $\sim 1 / 2$ IP. Hence the loss of energy and momentum from the ML by dispersion does very little to dampen entrainment, and the layer- 2 velocity contributes very little to the shear $\delta V$.

Over the short period of this model integration, the divergence of the interior velocity does not significantly alter the upwelling and pressure gradient within the interior. Hence, we see only the initial stage of the interior response and not a true internal wave (to be taken up elsewhere).

\section{d. The subsurface response of temperature}

The response of subsurface temperature sampled on a section across the hurricane track (Fig. 21) is qualitatively comparable to the Ella observations (Fig. 1b). It is not comparable in detail because the model ML has no transition layer (Price, 1979b), and because the hurricanes and oceanic initial conditions differ somewhat.

At depths within the initial ML $(30 \mathrm{~m})$ there is cooling due primarily to entrainment. At depths below the initial ML but within the final ML, the effect of entrainment is to cause warming. The warming is 

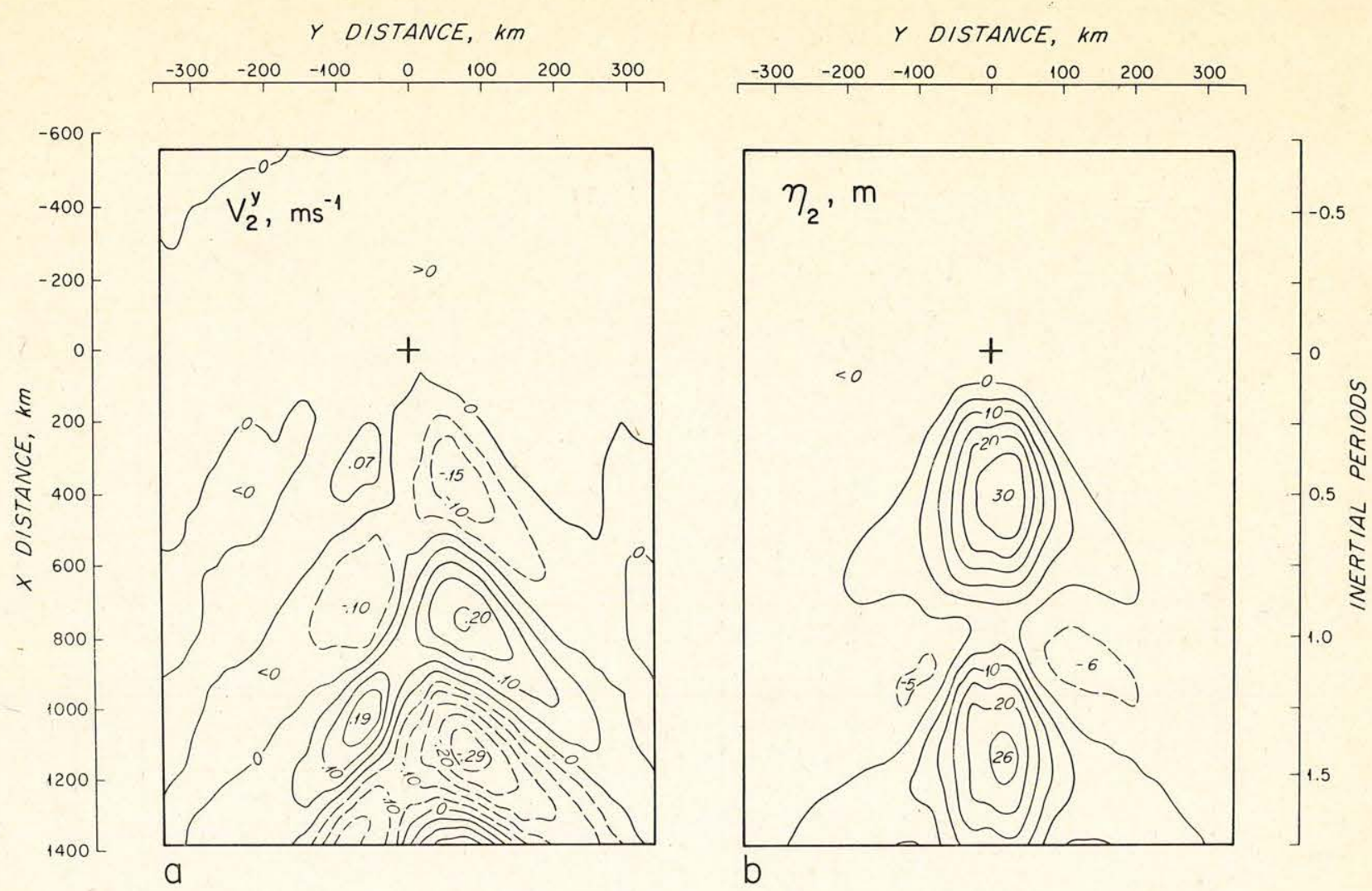

FIG. 20a. The $y$-component of layer-2 velocity for the EB-10/Eloise case. Contour interval is $0.05 \mathrm{~m} \mathrm{~s}^{-1}$. FIG. 20b. Upwelling at the base of layer 2. Contour interval is $5 \mathrm{~m}$.

most pronounced to the right of the track, beneath the region of maximum entrainment and cooling in the surface layer. Beneath the final ML, temperature is changed mainly by vertical advection (or upwelling). There is strong cooling directly beneath the track where upwelling is strongest. The magnitude of the cooling decreases with depth on account of a decrease in the vertical temperature gradient (rather than a decrease in upwelling amplitude). At some distance away from the track, weak downwelling causes a weak warming.

The axisymmetric model of Elsberry et al. (1976) differs considerably from the present model but includes two essential ingredients, upwelling and entrainment, required to arrive at a similar result.

\section{Comparison of the model solution with the EB-10 data}

The model solution sliced along Sec. B (Fig. 9) may be compared to the EB-10 observations. The solution is unique since there are no free or adjustable parameters. This greatly facilitates interpretation of model-data comparisons.

\section{a. Upwelling}

Subsurface temperature observations from EB-10 give a limited but useful description of the response in the interior. Below the ML the direct effect of wind-driven mixing and air-sea heat exchange vanish, and for most times and depths an advective heat balance should obtain. It is thus assumed that upwelling below the ML may be inferred from $53 \mathrm{~m}$ temperature observations, using corrected temperature $T, T_{0}$ and $\partial T / \partial z$ (Table 3 ), as

$$
\eta(t)=\frac{\left[T(t)-T_{0}\right]}{\partial T / \partial z} .
$$

There is no information in the EB-10 data set which permits a direct check of the assumptions in (12). Upwelling inferred from observations at 220 and 530 $\mathrm{m}$ provides some useful redundancy since the initial upwelling is expected to be in phase and of nearly equal magnitude through the main thermocline.

The observed $(53 \mathrm{~m})$ and predicted upwelling have very similar phase and magnitude over the first cycle (Fig. 22). The upwelling has an upward bias of $\approx 15$ $\mathrm{m}$, and oscillates with an amplitude of $\approx 13 \mathrm{~m}$. The 
first maximum of the oscillation occurs at $t=0.50$ IP and subsequent maxima follow at intervals of $\approx 0.95 \mathrm{IP}$. The upwelling oscillations at $220 \mathrm{~m}$ and $530 \mathrm{~m}$ are initially in phase with the upwelling at $53 \mathrm{~m}$ (noted in Section 2b1). The amplitude at $220 \mathrm{~m}$ may be estimated from the observed temperature oscillation (Fig. 5$)$ as $\left(0.5^{\circ} \mathrm{C}\right) /\left(0.035^{\circ} \mathrm{C} \mathrm{m}^{-1}\right)=14 \pm 2$ $\mathrm{m}$ (error bars estimated from uncertainty in vertical temperature gradient, Table 3 ), which is indistinguishable from the $53 \mathrm{~m}$ estimate. The amplitude at $530 \mathrm{~m}$ is somewhat larger, $22 \pm 7 \mathrm{~m}$, but more uncertain.

The amplitudes at 220 and $530 \mathrm{~m}$ are roughly constant during the several-day period following the hurricane. The $53 \mathrm{~m}$ upwelling appears to decay, and, by $t=4 \mathrm{IP}$, has nearly vanished. We know from Fig. 5 that the $53 \mathrm{~m}$ instrument was then within the ML, where $\partial T / \partial Z$ was drastically reduced. Hence the inference of $53 \mathrm{~m}$ upwelling from (12) becomes inappropriate beyond some unknown time $t \geq 1$ IP. There is no dynamical process inherent
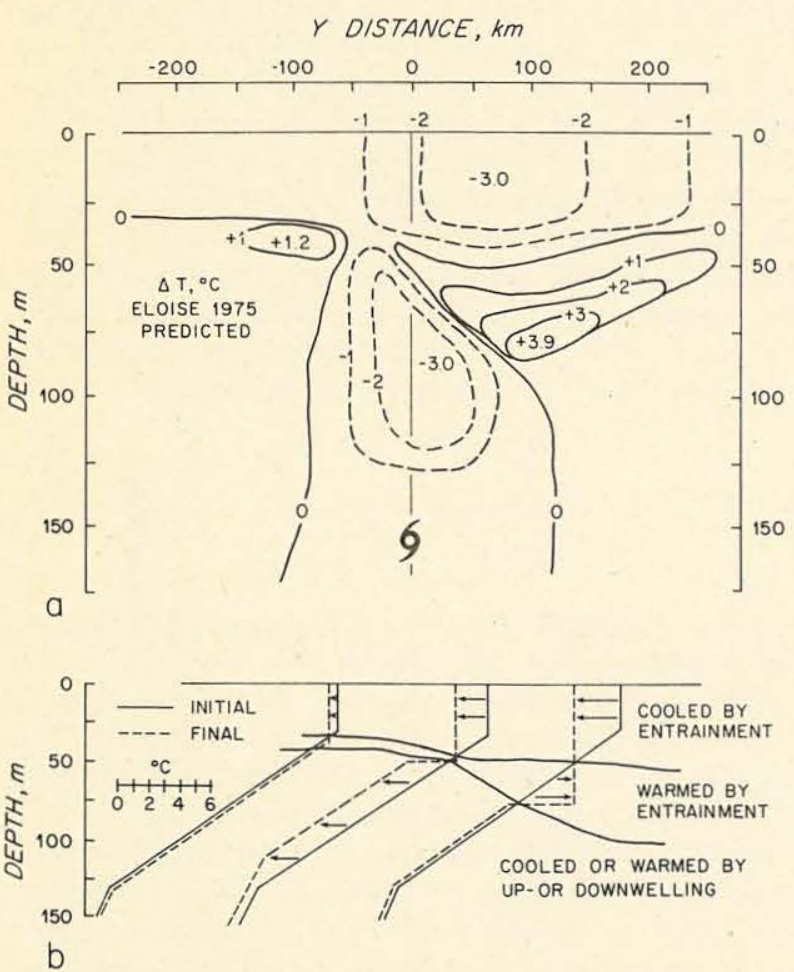

FIG. 21a. Predicted subsurface temperature response shown as a cross-track section for the EB-10 Eloise case. Contour interval is $1^{\circ} \mathrm{C}$, negative values are dashed. The model solution was sampled at $1.25 \mathrm{IP}$, when upwelling was roughly half-way between a maxima and a minima. A section made at $t=1.0$ or 1.5 IP would show considerably less or greater effect of vertical advection in the interior. This section is qualitatively comparable to the Fedorov et al. (1979, Fig. 1b) observed response.

FIG. 21b. Initial (solid) and final (dashed) temperature profiles at $y=-100,0,+100 \mathrm{~km}$. The process which dominates the heat budget is noted.

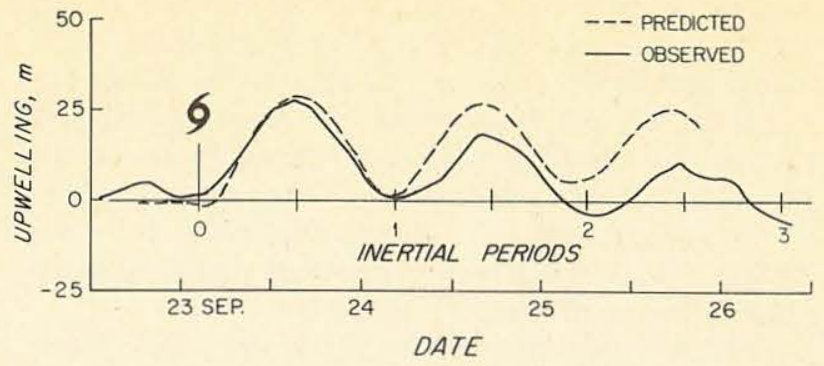

FIG. 22. Observed (solid) and predicted (dashed) upwelling below the base of the ML during the EB-10/Eloise event. Observed upwelling is inferred from a presumed vertical advective heat balance at $53 \mathrm{~m}$ depth. This fails sometime after about $t \approx 1 \mathrm{IP}$.

in the model that can lead to such a rapid decay of the upwelling. ${ }^{1}$ Perhaps horizontal advection of the upwelling away from EB-10 caused the apparent decay of the $53 \mathrm{~m}$ upwelling.

Sensitivity tests (discussed in Section 7b) indicate that any reasonable time-dependent model will give virtually the same prediction for the initial upwelling amplitude and phase. Hence the comparison of Fig. 22 is a test of the model forcing, and specifically of the wind-stress parameterization (8) and (9). If one applies a constant drag coefficient, $C_{D}=1.5 \times 10^{-3}$, the effect is to reduce the predicted upwelling by $\sim 40 \%$. This is well below what we observe, and it thus appears that a windspeed-dependent $C_{D}$ similar to Garratt's (1977) [e.g., Miller's (1964) or Smith's (1980)] is appropriate for use in hurricane conditions. (This says nothing about wind-speed dependence of $C_{D}$ at low wind speeds.)

\section{b. Sea surface temperature}

Observed and predicted SST may be compared directly (Fig. 23). The solution is in reasonable agreement with the observations during the period $t \leqslant 0.4$ IP when entrainment dominates the ML heat balance. The most prominent error is a phase lag of $\sim 0.1$ IP up to $t=0$, consistent with the phase error in the "model" $V_{1} h_{1}$ apparent in Fig. 13. Given that the forcing is approximately correct, the agreement is evidence that the entrainment parameterization (10) is appropriate for this case of strongly forced, highly time-dependent entrainment. This single, limitedprecision simulation does not, of course, constitute a rigorous test of (10).

Entrainment in the solution shuts off completely at $t=0.4 \mathrm{IP}$ when the wind stress begins to reduce the mean shear across the base of the ML (Fig. 16b). Thereafter the ML heat balance is dominated by

\footnotetext{
${ }^{1}$ An early version of the model which employed upwind firstdifferencing for the advective terms gave a "realistic" simulation of this decay on account of enormous artificial viscosity (e.g., Roache, 1976).
} 
horizontal advection (discussed in Section 5b). A minor increase in SST at $t=0.6 \mathrm{IP}$, followed by a significant decrease to $t=1.2 \mathrm{IP}$, occurs in both the observations and the prediction. The predicted SST continues to oscillate with a very regular near-inertial period, while the observed SST shows an irregular oscillation, though of similar amplitude. It is not known why this discrepancy arises during the advective phase of the SST response.

Entrainment dominates the ML heat budget. Along the track, the net (time-integrated from -1 to +1 IP) air-sea exchange is $0.2 \times 10^{2 \circ} \mathrm{C} \mathrm{m}(\sim 2 \mathrm{~K}$ cal $\mathrm{cm}^{-2}$ ); the net entrainment heat flux is $1.3 \times 10^{2 \circ} \mathrm{C} \mathrm{m}$ $\left(\sim 13 \mathrm{~K} \mathrm{cal} \mathrm{cm}^{-2}\right)$, or $\sim 85 \%$ of the total irreversible flux into the ML. This dominance of entrainment is general; it occurs also in the $y$-averaged heat budget, and in cases with different $U_{H}$ or oceanic initial conditions.

The EB-04 data (Fig. 7) demonstrate the dominant role of entrainment. The initial salinity profile at EB-04 (Fig. 11) included an anomalously fresh surface layer roughly $10 \mathrm{~m}$ thick overlying what was otherwise a $T, S$ profile very similar to that at EB-10. The initial ML thus had very large $\delta S$ and very small $\delta T$. As it began to deepen by entrainment there was thus a strong entrainment salt flux but little or no entrainment heat flux. Once the ML reached $30 \mathrm{~m}$ depth, where temperature stratification began, further entrainment caused significant SST decrease, but only modest further increase in ML salinity. If air-sea heat exchange were dominant instead, then a substantial SST reduction should have occurred during the first half of the response $(t \leqslant 0.2$ IP) when the ML was relatively thin and warm.

Entrainment is important also in the ML momentum balance. Because layer 2 is nearly quiescent during the entrainment process, entrainment acts simply to increase the ML thickness and decrease $V_{1}$ in inverse proportion. The more-than-factor-of-2 increase in ML depth by entrainment is thus crucial in determining the maximum ML velocity. [Were it not for this important feedback between ML velocity and the entrainment rate, a parameterization of the form (10), $W_{e} \sim R_{v}{ }^{-4} \sim \delta V^{8}$, would be hopelessly unstable.]

The wind speed-dependence of $C_{Q}$ is difficult to infer from these simulations because air-sea exchange is such a small component of the ML heat budget. ${ }^{2}$ By contrast, the EB-10/Eloise case run with a constant drag coefficient $C_{D}=1.5 \times 10^{-3}$ gives greatly

\footnotetext{
${ }^{2}$ We are able, however, to rule out the order of magnitude increase of $C_{Q}$ inferred by Pudov et al. (1979) and Fedorov et al. (1979) from observations of the change in upper ocean heat content. Fig. 21 suggests that most of the apparent change in heat content of a water column is due to entrainment or upwelling (depending on column depth).
}

reduced entrainment and an SST response $\sim 40 \%$ below that observed.

\section{Numerical experiments \\ a. Parametric dependence}

Numerical experiments show the dependence of the upper ocean response on the parameters that characterize the hurricane and the ocean. A hurricane is characterized mainly by its strength, translation speed and size; the ocean is characterized mainly by the initial ML depth, the temperature gradient in layer 2, and the local inertial period. To discern the dependence of the response on these features, a single parameter was varied over a realizable range, with all other parameters fixed to the EB-10/Eloise values (which seem fairly typical). Hurricane strength was varied through a factor multiplying the Eloise wind profile; it is specified by $U_{10 \max }$. Hurricane size was varied by stretching the radial coordinate of the Eloise wind profile; it is specified by the radius at which the wind speed equals $1 / 2 U_{10 \text { max }}$. The ocean's response is described by $\Delta \overline{\mathrm{SST}}^{y}$, the $y$-averaged $\Delta$ SST along Section A, by $\Delta \mathrm{SST}_{\max }$, and by $V_{1 \max }$, the maximum ML current, which occurs anywhere between $-800<x<800 \mathrm{~km}$.

The dependence of $\Delta \overline{\mathrm{SST}}^{y}, \Delta \mathrm{SST}_{\max }, V_{1 \max }$ on all parameters is roughly linear and can be summarized by the derivatives $\partial$ (response) $/ \partial$ (parameter) evaluated around the EB-10/Eloise case (Table 5 ), as in a Taylor's series expansion. Given the response from the EB-10/Eloise case,

$$
\begin{aligned}
\Delta \overline{\mathrm{SST}}^{y} & =-1.6^{\circ} \mathrm{C}, \\
\Delta \mathrm{SST}_{\max } & =-3.1^{\circ} \mathrm{C}, \\
V_{1 \max } & =1.1 \mathrm{~m} \mathrm{~s}^{-1},
\end{aligned}
$$

we can estimate the response when one or more air-sea parameters are varied.

The ocean response shows a significant dependence on both hurricane and ocean parameters. The SST response is large for strong, slowly moving hurricanes. Because entrainment dominates the ML heat balance, the SST response is large when there is cold water near the sea surface, i.e., when the initial ML depth is shallow and when the temperature gradient beneath the ML is sharp. Two results are somewhat surprising. (1) The maximum ML current is relatively insensitive to everything except hurricane strength, and is $1.1 \pm 0.2 \mathrm{~m} \mathrm{~s}^{-1}$ over a parameter range within which the SST response varies considerably. This occurs because of the important feedback between entrainment and the ML velocity magnitude noted in Section 6c. (2) The response of $\Delta$ $\mathrm{SST}_{\max }$ is quite insensitive to hurricane size and to the local inertial period. This occurs because there 
TABLE 5. Variation of the oceanic response with variation in air-sea parameters.

\begin{tabular}{|c|c|c|c|c|c|c|c|c|}
\hline $\begin{array}{c}\text { Air-sea } \\
\text { parameter }\end{array}$ & $\begin{array}{l}\text { EB-10/Eloise } \\
\text { value }\end{array}$ & $\frac{\partial \Delta \overline{\mathrm{SST}}^{y}}{\partial(\quad)}$ & $\frac{\partial \Delta \mathrm{SST}_{\max }}{\partial(\quad)}$ & $\frac{\partial V_{1 \max }}{\partial(\quad)}$ & $\begin{array}{l}\text { Plausible } \\
\text { range of } \\
\text { air-sea } \\
\text { parameter }\end{array}$ & $\begin{array}{l}\text { Conse- } \\
\text { quent } \\
\text { range of } \\
\Delta \overline{\mathrm{SST}}^{y} \\
\left({ }^{\circ} \mathrm{C}\right)\end{array}$ & $\begin{array}{l}\text { Conse- } \\
\text { quent } \\
\text { range of } \\
\Delta \mathrm{SST}_{\max } \\
\left({ }^{\circ} \mathrm{C}\right)\end{array}$ & $\begin{array}{c}\text { Conse- } \\
\text { quent } \\
\text { range of } \\
V_{1 \max } \\
\left(\mathrm{m} \mathrm{s}^{-1}\right)\end{array}$ \\
\hline $\begin{array}{l}\text { Hurricane wind } \\
\text { speed } U_{10 \max }\end{array}$ & $35 \mathrm{~m} \mathrm{~s}^{-1}$ & $-0.14^{\circ} \mathrm{C} \mathrm{m}^{-1} \mathrm{~s}$ & $-0.24^{\circ} \mathrm{C} \mathrm{m}^{-1} \mathrm{~s}$ & 0.047 & $10 \mathrm{~m} \mathrm{~s}^{-1}$ & 1.4 & 2.4 & 0.5 \\
\hline $\begin{array}{l}\text { Hurricane }^{\mathrm{b}} \\
\text { translation } \\
\text { speed } U_{H}\end{array}$ & $8.5 \mathrm{~m} \mathrm{~s}^{-1}$ & $0.18^{\circ} \mathrm{C} \mathrm{m}^{-1} \mathrm{~s}$ & $0.31^{\circ} \mathrm{C} \mathrm{m}^{-1} \mathrm{~s}$ & -0.023 & $5 \mathrm{~m} \mathrm{~s}^{-1}$ & 0.9 & 1.5 & 0.1 \\
\hline Hurricane size & $250 \mathrm{~km}$ & $-0.004^{\circ} \mathrm{C} \mathrm{km}^{-1}$ & $\begin{array}{l}-5 \times 10^{-4} \\
{ }^{\circ} \mathrm{C} \mathrm{km}^{-1}\end{array}$ & $\begin{array}{l}7 \times 10^{-4} \\
\mathrm{~m} \mathrm{~s}^{-1} \mathrm{~km}^{-1}\end{array}$ & $100 \mathrm{~km}$ & 0.4 & 0.05 & 0.1 \\
\hline $\begin{array}{r}\text { Initial ML } \\
\text { depth } h_{1}\end{array}$ & $30 \mathrm{~m}$ & $0.03^{\circ} \mathrm{C} \mathrm{m}^{-1}$ & $0.06^{\circ} \mathrm{C} \mathrm{m}^{-1}$ & $-0.005 \mathrm{~s}^{-1}$ & $20 \mathrm{~m}$ & 0.6 & 1.2 & 0.1 \\
\hline $\begin{array}{l}\text { Temperature } \\
\text { gradient } \\
\partial T_{2} / \partial z\end{array}$ & $0.125^{\circ} \mathrm{C} \mathrm{m}^{-1}$ & $-10.0 \mathrm{~m}$ & $-19.10 \mathrm{~m}$ & $\begin{array}{l}1.91 \mathrm{~m}^{2} \mathrm{~s}^{-1} \\
\left({ }^{\circ} \mathrm{C}\right)^{-1}\end{array}$ & $0.1^{\circ} \mathrm{C} \mathrm{m}^{-1}$ & 1.0 & 1.9 & 0.2 \\
\hline $\begin{array}{l}\text { Inertial period } \\
\qquad 2 \pi / f\end{array}$ & 1.08 day & $-0.26^{\circ} \mathrm{C}$ day $^{-1}$ & $-0.11^{\circ} \mathrm{C}$ day $^{-1}$ & $\begin{array}{c}0.09 \mathrm{~m} \mathrm{~s}^{-1} \\
\text { day }^{-1}\end{array}$ & 1.0 day & 0.3 & 0.1 & 0.1 \\
\hline
\end{tabular}

${ }^{\text {a }}$ Range (standard deviation) over many individual cases.

' The dependence of $\Delta$ SST on $U_{H}$ shows some negative curvature which causes a roughly $20 \%$ underprecipitation of $\Delta$ SST at very small and large $U_{H}, 2$ and $16 \mathrm{~m} \mathrm{~s}^{-1}$.

is a wide range of space scales in a hurricane wind field, and a roughly resonant coupling between ML current and wind stress will occur over a wide range of latitudes and hurricane sizes. The point of the maximum SST response shifts further rightward as the inertial period increases and the point of maximum coupling between wind stress and ML current shifts to larger radius where the wind-stress vector turns more slowly.

The uncertainty in the SST simulation of the EB10/Eloise case (Fig. 23) due to uncertainty in the initial condition may be assessed from these results. The uncertainty in initial ML depth was estimated to be $\pm 5 \mathrm{~m}$. Given that the $53 \mathrm{~m}$ temperature in the initial profile is correct, this must be accompanied by a corresponding uncertainty in the temperature gradient of $\pm 0.025^{\circ} \mathrm{C} \mathrm{m}^{-1}$. To estimate the consequent uncertainty in the SST simulation we use the derivatives for $\Delta \overline{\operatorname{SST}}^{y}[\sim \Delta \operatorname{SST}(y=0)]$ and compute $5 \mathrm{~m} \times 0.03^{\circ} \mathrm{C} \mathrm{m}^{-1}+0.025^{\circ} \mathrm{C} \mathrm{m}^{-1} \times(-10 \mathrm{~m})$ $=0.10^{\circ} \mathrm{C}$, the half-width of the error bar given for the simulation.

Within the major subtropical ocean gyres the ML depth and upper-thermocline temperature gradient covary in a way that leads to a striking geographic variation in the SST response to a given hurricane. An example is taken from Fuglister's (1960) hydrographic section made across the Atlantic Ocean along $16^{\circ} \mathrm{N}$ during early fall. At $20^{\circ} \mathrm{W}$, near the eastern boundary, where the main thermocline is shallow, the ML depth is $30 \mathrm{~m}$ and the upper thermocline temperature gradient is very strong, $0.25^{\circ} \mathrm{C} \mathrm{m}^{-1}$. At $55^{\circ} \mathrm{W}$, near the western boundary, where the thermocline is relatively deep, the values are $50 \mathrm{~m}$ and $0.05^{\circ} \mathrm{C} \mathrm{m}^{-1}$. The SST is nearly the same at both locations. The response of $\Delta \overline{\mathrm{SST}}^{y}$ for $20^{\circ} \mathrm{W}$ conditions is estimated to be $\sim-2.9^{\circ} \mathrm{C}$, which is a significant fraction of usual tropical air-sea temperature differences. For $55^{\circ} \mathrm{W}$ conditions the response is much smaller, $\sim-0.3^{\circ} \mathrm{C}$, mainly on account of the weak upper thermocline temperature gradient.

\section{b. Dynamical experiments}

To assess directly the effects of nonlocal dynamical processes we can selectively switch off nonlocal terms in the model equations. This is done in two stages; first the pressure gradients are switched off, and then all the advective terms. Each grid point then operates independently of its neighbors, and the three-dimensional model has become an array of one-dimensional models.

All nonlocal effects are negligibly small in the response of $\Delta \overline{\mathrm{SST}}^{y}, \Delta \mathrm{SST}_{\max }$ and $V_{1 \max }$ to a very rapidly moving hurricane (Fig. 24, Table 6). Horizontal advection is important in the pointwise balance, and causes the relative displacement of the curves.

Nonlocal effects, and especially upwelling, are important in several aspects of the response to a slowly moving hurricane, $U_{H}=4 \mathrm{~m} \mathrm{~s}^{-1}$. When pressure gradients are omitted, $\Delta \mathrm{SST}_{\max }$ and $V_{1 \max }$ are over- 


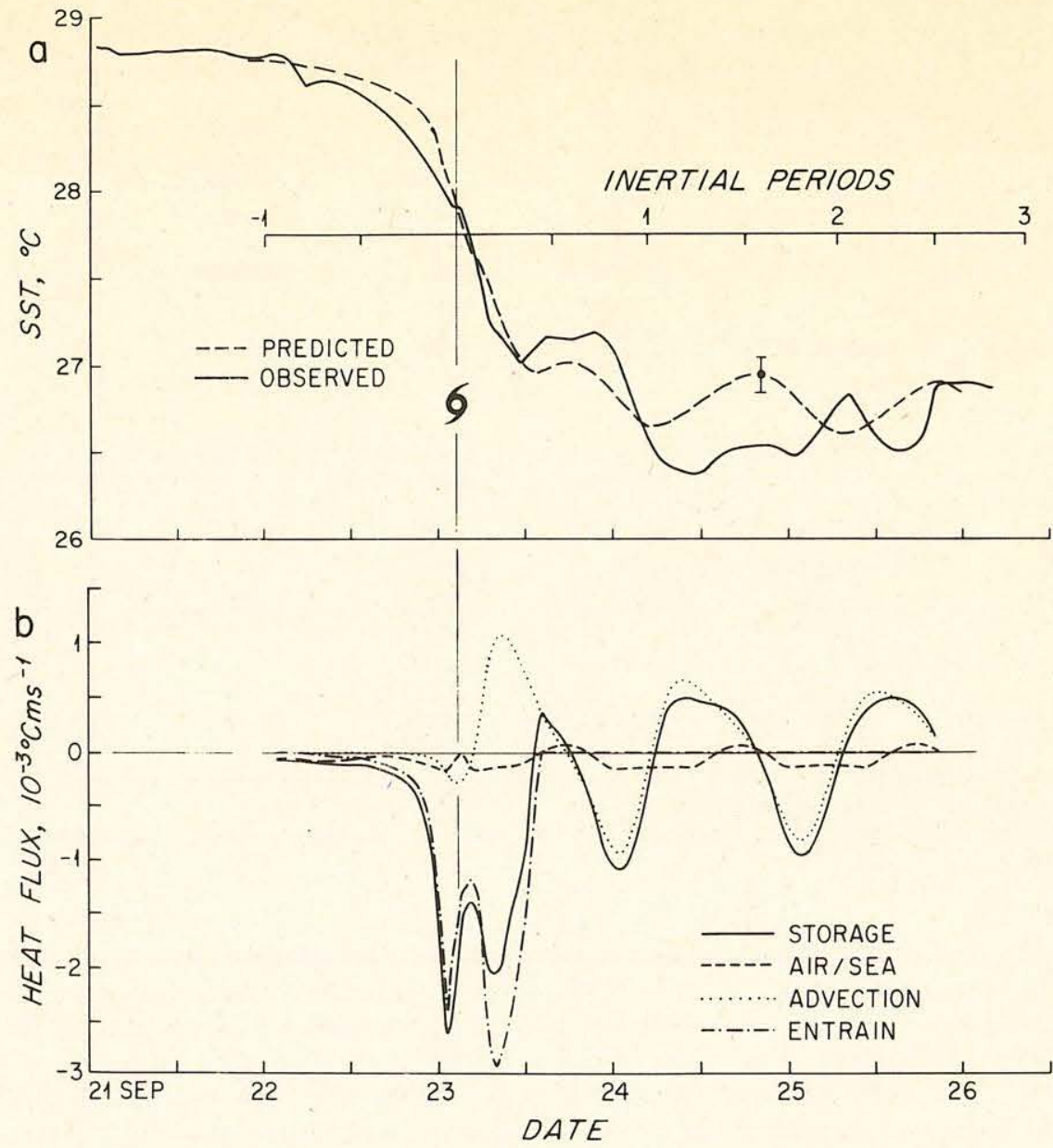

FIG. 23a. Observed (solid) and predicted (dashed) sea surface temperature for the EB-10/Eloise event. The error bar shown on the predicted curve at (arbitrarily) $t=1.6$. IP is due to the uncertainty in the initial condition (computed in Section 7).

FIG. 23b. The ML heat balance for the simulation of the EB-10/Eloise event (kinematic units). The terms in this heat balance are the same as in the ML temperature balance [Eq. (2a)] multiplied by $h_{1}$.

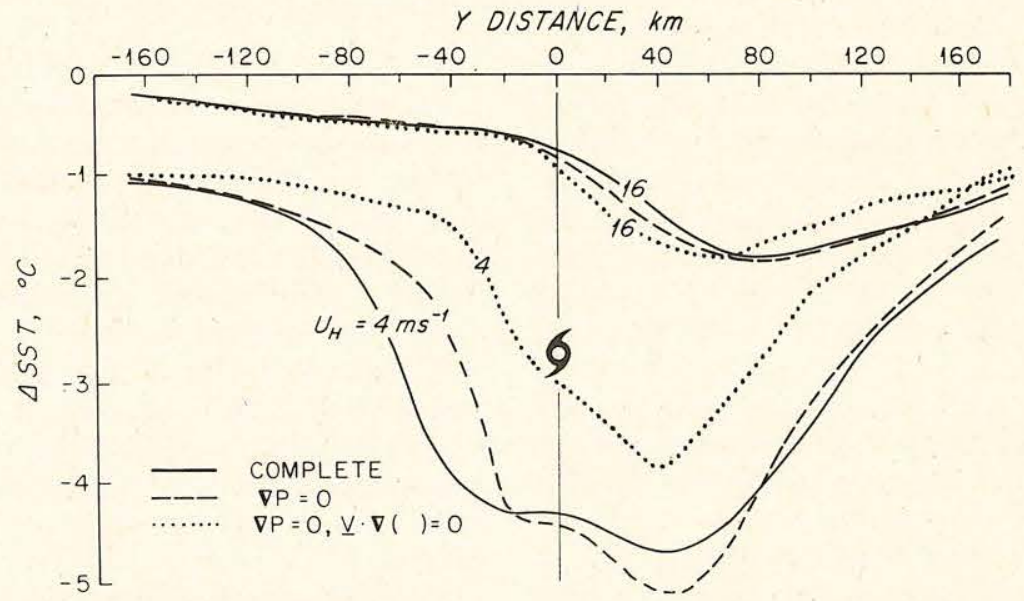

FIG. 24. SST response for hurricane translating at $U_{H}=4$ and $16 \mathrm{~m} \mathrm{~s}^{-1}$. The solid curves are predictions of the full model; dashed curves are the predictions when pressure gradients are set to zero; dotted curves are the predictions when all nonlocal terms are set to zero. Note that the model predictions are quite similar for a very rapidly moving hurricane but diverge considerably for a slowly moving hurricane. 
TABLE 6. Dynamical experiments.

\begin{tabular}{|c|c|c|c|c|c|c|}
\hline \multirow[b]{2}{*}{ Model } & \multicolumn{3}{|c|}{ Slowly moving, $U_{H}=4 \mathrm{~m} \mathrm{~s}^{-1}$} & \multicolumn{3}{|c|}{ Rapidly moving, $U_{H}=16 \mathrm{~m} \mathrm{~s}^{-1}$} \\
\hline & $\begin{array}{c}\Delta \overline{\mathrm{SST}}^{y} \\
\left({ }^{\circ} \mathrm{C}\right)\end{array}$ & $\begin{array}{l}\Delta \mathrm{SST}_{\max } \\
\left({ }^{\circ} \mathrm{C}\right)\end{array}$ & $\begin{array}{c}V_{1 \max } \\
\left(\mathrm{m} \mathrm{s}^{-1}\right)\end{array}$ & $\underset{\left({ }^{\circ} \mathrm{C}\right)}{\Delta \overline{\mathrm{SST}}^{y}}$ & $\begin{array}{c}\Delta \mathrm{SST}_{\max } \\
\left({ }^{\circ} \mathrm{C}\right)\end{array}$ & $\begin{array}{c}V_{1 \max } \\
\left(\mathrm{m} \mathrm{s}^{-1}\right)\end{array}$ \\
\hline Complete & -2.59 & -4.73 & 1.17 & -1.01 & -1.87 & 0.96 \\
\hline $\begin{array}{l}\text { Pressure gradients } \\
\text { vanish } \\
\text { All nonlocal terms }\end{array}$ & -2.54 & -5.33 & 1.35 & -1.03 & -1.99 & 0.99 \\
\hline vanish & -1.86 & -4.00 & 1.54 & -0.98 & -1.84 & 0.99 \\
\hline
\end{tabular}

estimated by $\sim 10 \%$, and the $y$ profile of $\Delta$ SST is distorted somewhat; $\Delta \overline{\mathrm{SST}}^{y}$ is almost unaltered. Thus pressure gradients do not greatly affect the entrainment response. When advection (and hence upwelling) is also omitted, $\Delta \overline{\mathrm{SST}}^{y}$ is underestimated by $\sim 20 \%$, and the SST response near the track is underestimated by $\sim 35 \%$. Under a slowly moving hurricane, massive upwelling occurs simultaneously with entrainment (Fig. 25) and enhances entrainment by reducing the ML thickness. For very slowly moving hurricanes, $\Delta \mathrm{SST}_{\max }$ occurs nearly along the track (Fig. 26). The SST response remains more extensive on the right side of the track because the left-right asymmetry in wind-stress turning still operates, though with less efficiency.

\section{Conclusions and remarks}

1) Entrainment is the primary mechanism that lowers the SST beneath a moving hurricane. Air-sea heat exchange plays only a minor role.

The well-documented rightward bias in the response of SST occurs (in this model) because the asymmetry in turning direction of the wind-stress vector drives a very strong asymmetry in the ML velocity, and thus in entrainment. The probable asymmetry in stress magnitude contributes only slightly to the asymmetry in SST response.

2) The SST response is a lively function of (in rough order of importance) hurricane strength and translation speed, and of the initial ML depth and upper thermocline temperature gradient. The maximum ML velocity is insensitive to all but hurricane strength. The response is a weak function of latitude and hurricane size.

3) Upwelling causes a significant enhancement of the SST response to a slowly moving hurricane $\left(U_{H}\right.$ $\approx 4 \mathrm{~m} \mathrm{~s}^{-1}$ ) but only a negligible one for rapidly moving hurricanes. Horizontal advection is important in the pointwise balances after a hurricane passage. Pressure gradients and the response in the interior are of relatively minor importance.

4) The EB-10/Eloise case provides evidence that Garratt's (1977) wind-speed-dependent drag coefficient and the entrainment law (10) are appropriate for hurricane conditions. Simulations are not sensitive to variations in the air-sea heat-transfer coefficients.

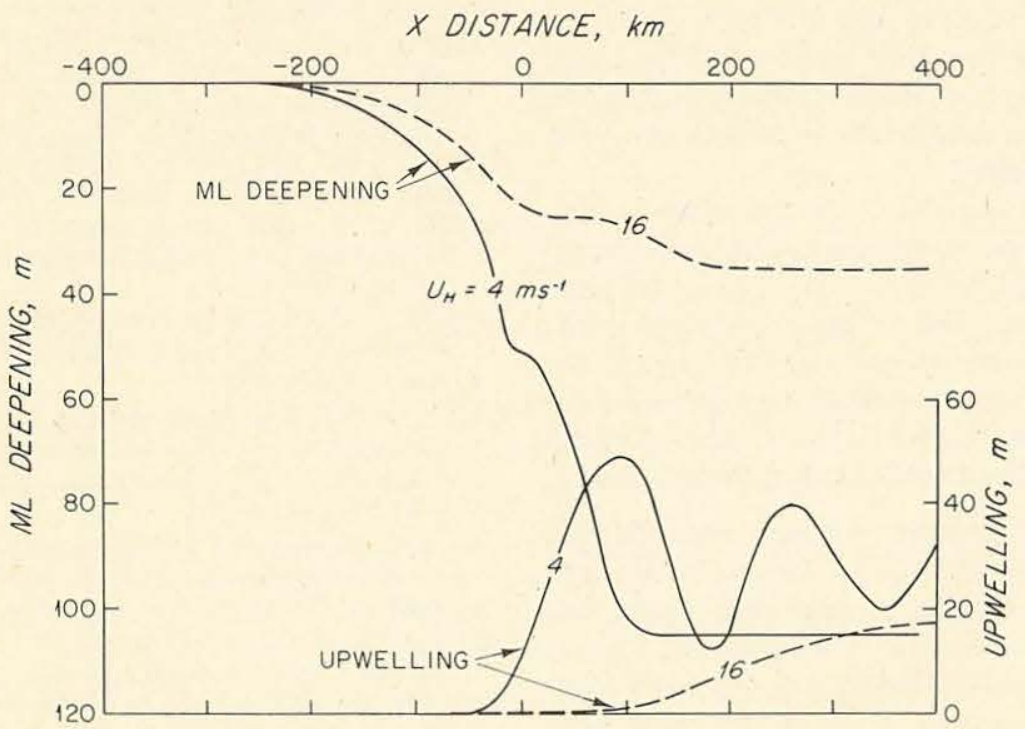

FIG. 25. Upwelling and change in ML depth due to entrainment for hurricanes moving at $U_{H}=4$ and $16 \mathrm{~m} \mathrm{~s}^{-1}$. The abscissa is $x$ distance; time runs faster by a factor of 4 for the case $U_{H}=4 \mathrm{~m} \mathrm{~s}^{-1}$. 


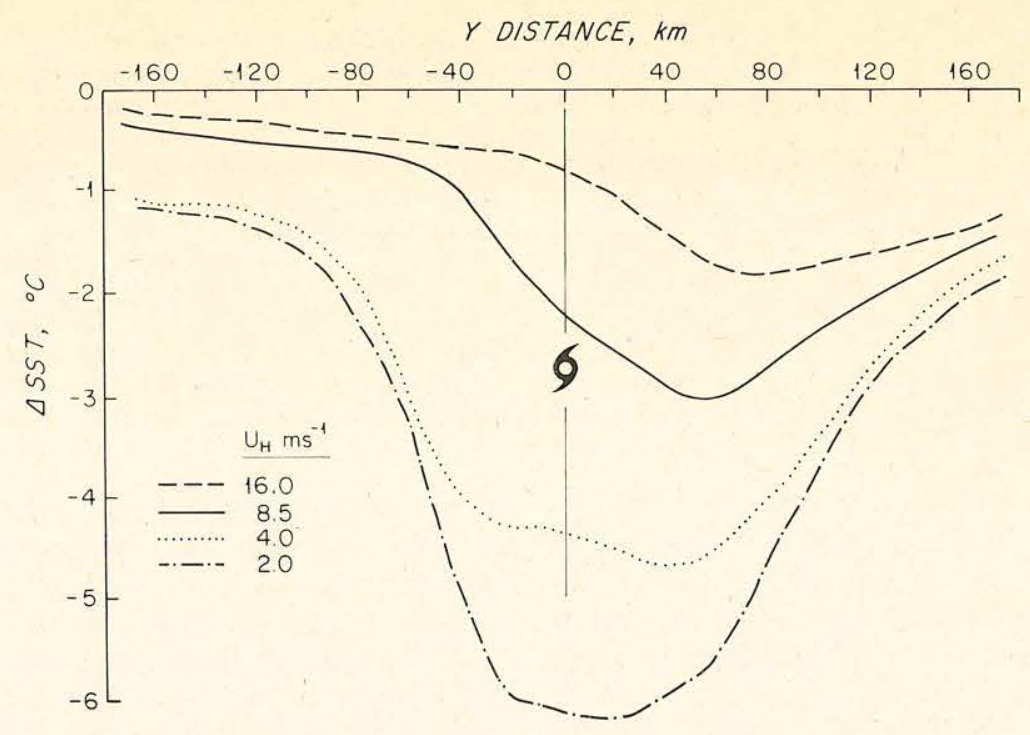

FIG. 26. Cross-track (section A) profile of $\Delta$ SST for different hurricane translation speeds.

When assessing the role of nonlocal effects, we should keep in mind that hurricanes are extraordinarily powerful, small-scale storms. For the vast majority of storms, we would expect nonlocal effects to be smaller, and probably negligible. This is good news. It suggests that for some purposes, e.g., short-term SST prediction, it will not be necessary to have mixed-layer dynamics closely coupled with mesoscale response dynamics. (Important nonlocal effects may also arise from inhomogeneities of the initial condition or from coastal boundary effects.)

The air-sea data set from EB-10 demonstrates the great potential that the large environmental data buoys have for oceanography. These buoys can produce high-quality long-term observations under extremely harsh conditions. Thermistor strings and sufficient pressure sensors to determine mooring line configuration should ideally be included in every operational deployment.

The great range of the SST response and its sensitive dependence upon some hurricane and ocean parameters make the air-sea interaction problem especially interesting. The largest response $-6^{\circ} \mathrm{C}$ is a significant fraction of normal tropical air-sea temperature differences and must reduce evaporation significantly. The effect on hurricane strength may thus be important but remains to be demonstrated.

Acknowledgments. Support for this research was provided by the Office of Naval Research through Contract N00014-76-C-0226. I am grateful to Russell Elsberry, Lee Gordon, Raymond Schmitt and Robert Weller for their helpful comments on this work, and to Karin Bohr and Audrey Williams for their help in preparing the manuscript.

\section{REFERENCES}

Cardone, V. J., D. B. Ross and M. R. Ahrens, 1977: An experiment in forecasting hurricane generated sea state. Preprints Ilth Tech. Conf. Hurricanes and Tropical Meteorology, Miami Beach, Amer. Meteor. Soc., 688-695.

Chang, S. W., and R. A. Anthes, 1978: Numerical simulations of the ocean's nonlinear baroclinic response to translating hurricanes. J. Phys. Oceanogr., 8, 468-480.

- , and -1979 : The mutual response of the tropical cyclone and the ocean. J. Phys. Oceanogr., 9, 128-135.

Elsberry, R., T. Fraim and R. Trapnell, Jr., 1976: A mixed layer model of the oceanic thermal response to hurricanes. J. Geophys. Res., 81, 1153-1162.

Fedorov, K. N., A. A. Varfolomeev, A. I. Ginzburg, A. G. Zatsepin, A. Yu. Krasnopevtsev, A. G. Ostrovsky and V. E. Skylarov, 1979: Thermal reaction of the ocean on the passage of the hurricane Ella. Okeanologiya, 19, 992-1001.

Fuglister, F. C., 1960: Atlantic Ocean Atlas of Temperature and Salinity Profiles and Data from the International Geophysical Year of 1957-1958. Woods Hole Oceanographic Institution Atlas Series, Vol. 1, 209 pp.

Garratt, J. R., 1977: Review of drag coefficients over oceans and continents. Mon. Wea. Rev., 105, 915-929.

Geisler, J. E., 1970: Linear theory of the response of a twolayer ocean to a moving hurricane. Geophys. Fluid Dyn., $1,249-272$.

Gonella, J., 1972: A rotary component method for analysing meteorological and oceanographic vector time series. Deep-Sea Res., 19, 833-846.

Ichiye, T., 1972: Circulation changes caused by hurricanes. Contributions on the Physical Oceanography of the Gulf of Mexico, L. R. A. Capurro and J. L. Reid, Eds., Gulf Publishing Co., 229-257.

_- 1977: Response of a two-layer ocean with a baroclinic current to a moving storm, Part II - non-geostrophic baroclinic mode. J. Oceanogr. Soc. Japan, 33, 169-182.

Imberger, J., J. C. Patterson and W. J. Wiebe, 1979: Tropical cyclones: nature's ploughs on the northwest shelf of Australia. Paper presented at the International Conference on Tropical Cyclones, Perth, Australia, 1979.

Iverson, R. L., 1977: Mesoscale oceanic phytoplankton patchi- 
ness caused by hurricane effects on nutrient distribution in the Gulf of Mexico. Oceanic Sound Scattering Predictions, N. R. Anderson and B. J. Zahuranec, Eds., Plenum Press, 767-778.

Johnson, A., and G. A. Speer, 1978: Data report: Buoy observations during Hurricane Belle, August 1976. National Space Technology Laboratories, NSTL Station, MS, $22 \mathrm{pp}$.

Jordan, C. L., 1964: On the influence of tropical cyclones on the sea surface temperature.Proc. Symp. Tropical Meteorology, Wellington, New Zealand Meteor. Serv., 614-622.

Kantha, L. H., O. M. Phillips and R. S. Azad, 1978: On turbulent entrainment at a stable density interface. J. Fluid Mech., 79, $753-768$.

Kato, H., and O. M. Phillips, 1969: On the penetration of a turbulent layer into stratified fluid. J. Fluid Mech., 37, 643-655.

Leipper, D. F., 1967: Observed ocean conditions and Hurricane Hilda, 1964. J. Atmos. Sci., 24, 182-196.

Malkus, J. S., 1962: Large-scale interactions. The Sea: Ideas and Observations on Progress in the Study of the Seas, Vol. 1, Physical Oceanography. M. N. Hill, Ed., Interscience, 88294.

Miller, B. J., 1964: A study of the filling of Hurricane Donna (1960) over land. Mon. Wea. Rev., 92, 389-406.

Niiler, P. P., and E. B. Kraus, 1977. One-dimensional models of the upper ocean. Modelling and Prediction of the Upper Layers of the Ocean, E. B. Kraus, Ed., Pergamon Press, $143-172$.

O'Brien, J. J., R. M. Clancy, A. J. Clarke, M. Crepon, R. Elsberry, T. Gammelsrød, M. MacVean, L. P. Röed and J. D. Thompson, 1977: Upwelling in the ocean: two- and threedimensional models of upper ocean dynamics and variability.
Modelling and Prediction of the Upper Layers of the Ocean, E. B. Kraus, Ed., Pergamon Press, 178-228.

, and R. O. Reid, 1967: The non-linear response of a twolayer baroclinic ocean to a stationary, axially-symmetric hurricane: Part I. J. Atmos. Sci., 24, 197-207.

Ooyama, K., 1969: Numerical simulation of the life cycle of tropical cyclones. J. Atmos. Sci., 26, 3-40.

Pollard, R. T., P. B. Rhines and R. O. R. Y. Thompson, 1973: The deepening of the wind-driven layer. Geophys. Fluid Dyn., 4, 381-404

Price, J. F., 1979a: On the scaling of stress driven entrainment experiments. J. Fluid Mech., 90, 509-529.

- 1979b: Observations of a rain-formed mixed-layer. J. Phys. Oceanogr., 9, 643-649.

- C. N. K. Mooers and J. C. Van Leer, 1978: Observation and simulation of storm-induced mixed-layer deepening. $J$. Phys. Oceanogr., 8, 582-599.

Pudov, V. D., A. A. Varfolomeev and K. N. Fedorov, 1979: Vertical structure of the wake of a typhoon in the upper ocean. Okeanologiya, 21, 142-146.

Roache, P. J., 1976: Computational Fluid Dynamics. Hermosa Publ., 446 pp.

Smith, S. D., 1980: Wind stress and heat flux over the ocean in gale force winds. J. Phys. Oceanogr., 10, 709-726.

Turner, J. S., 1973: Buoyancy Effects in Fluids. Cambridge University Press, $367 \mathrm{pp}$.

Withee, G. W., and A. Johnson, 1976: Data report: Buoy observations during Hurricane Eloise (September 19 to October 11, 1975). U.S. Department of Commerce, NOAA, NSTL Station, Mississippi, $21 \mathrm{pp}$.

Wright, R., 1969: Temperature structure across the Kuroshio before and after Typhoon Shirley. Tellus, 21, 409-413. 


\section{MANDATORY DISTRIBUTION LIST}

FOR UNCLASSIFIED TECHNICAL REPORTS, REPRINTS, AND FINAL REPORTS PUBLISHED BY OCEANOGRAPHIC CONTRACTORS

OF THE OCEAN SCIENCE AND TECHNOLOGY DIVISION

OF THE OFFICE OF NAVAL RESEARCH

\section{(REVISED NOVEMBER 1978)}

1 Deputy Under Secretary of Defense (Research and Advanced Technology) Military Assistant for Environmental Science Room 30129

Washington, D.C. 20301

Office of Naval Research 800 North Quincy Street

Arlington, VA 22217

3 ATTN: Code 483

1 ATTN: Code 460

2 ATTN: 102B

1 CDR J. C. Harlett, (USN) ONR Representative Woods Hole Oceanographic Inst.

Woods Hole, MA 02543

Commanding officer Naval Research Laboratory Washington, D.C. 20375

6 ATTN: Library, Code 2627
12 Defense Documentation Center Cameron Station

Alexandria, VA 22314 ATTN: DCA

\section{Commander}

Naval Oceanographic Office NSTL Station

Bay St. Louis, MS 39522

1 ATTN: Code 8100

1 ATTN: Code 6000

1 ATTN: Code 3300

1 NODC/NOAA

Code $D 781$

Wiscons in Avenue, N.W. Washington, D.C. 20235 
UNCLASSIFIED $\quad 7 / 81$

SECURITY CLASSIFICATION OF THIS PAGE (When Data Entored)

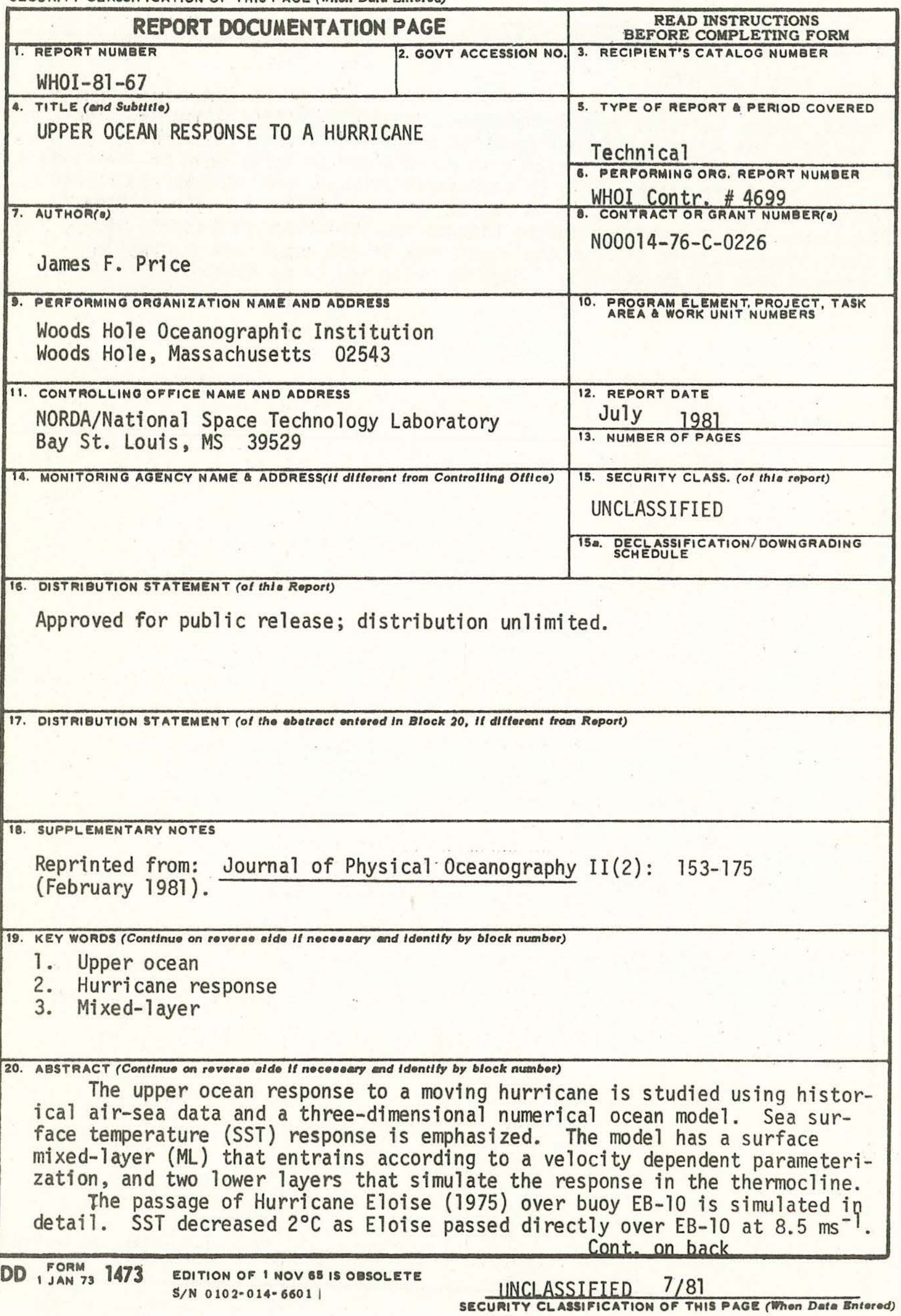


Cont. from block 20.

Model results indicate that entrainment caused $85 \%$ of the irreversible heat flux into the ML; air-sea heat exchange accounted for the remainder. The maximum SST response was predicted to be $-3^{\circ} \mathrm{C}$ and to occur $60 \mathrm{~km}$ to the right of the hurricane track. This is consistent with the well-documented rightward bias in the SST response to rapidly moving hurricanes. The rightward bias occurs in the model solution because the hurricane wind-stress vector turns clockwise with time on the right side of the track and is roughly resonant with the ML velocity. High ML velocites cause strong entrainment and thus a strong SST response. 


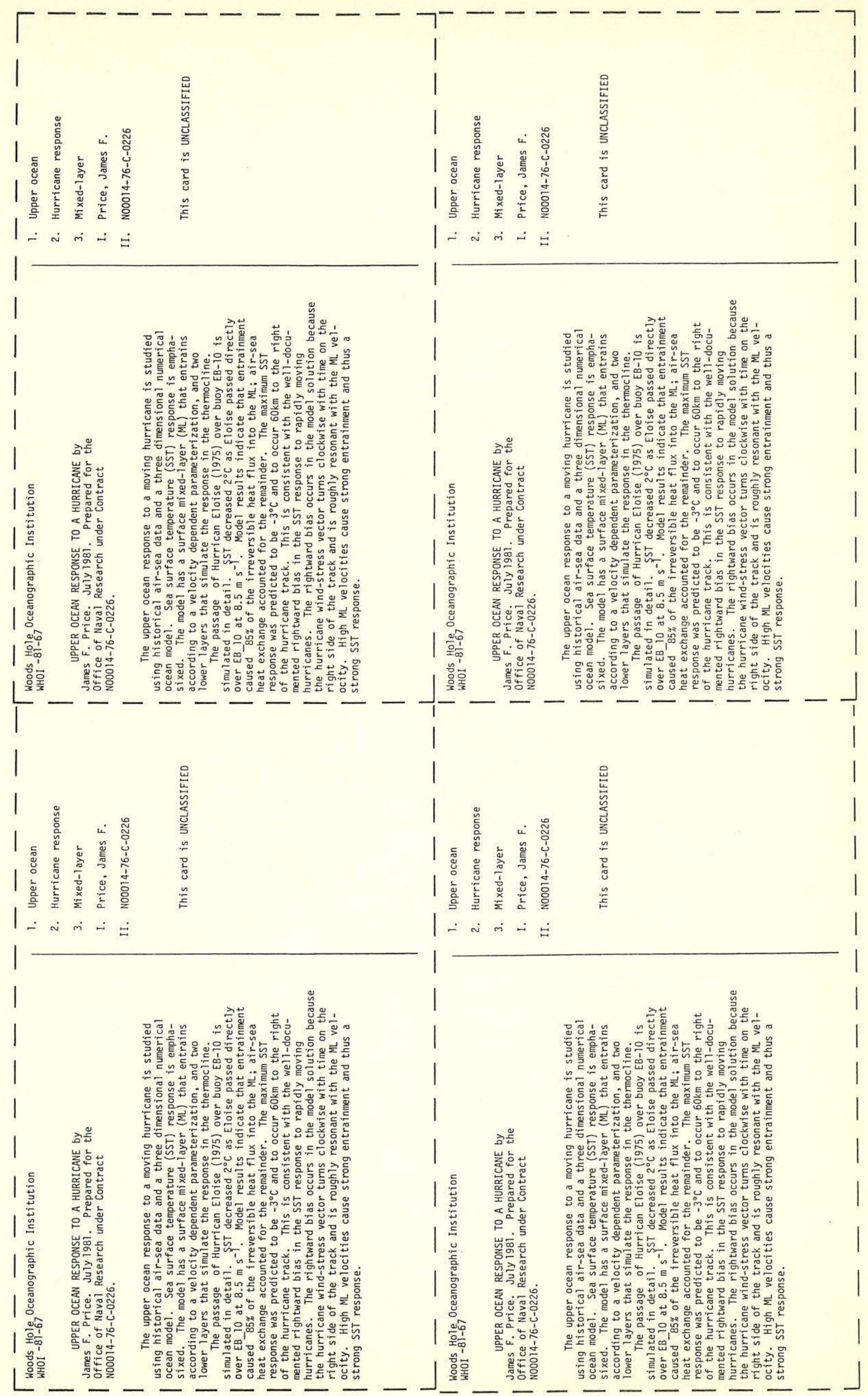

